\title{
O QUE SABEMOS SOBRE A RELAÇÃO DAS MULHERES COM O TURISMO DE AVENTURA E ECOTURISMO?
}

Programa de Pós-graduação em Turismo da Universidade de São Paulo ivaneli@usp.br

Amanda Alves Borges Mestranda

Programa de Pós-graduação em Turismo da Universidade de São Paulo amanda.borges@usp.br

Pedro Scrivano Mestrando

Programa de Pós-graduação em Turismo da Universidade de São Paulo pedro.scrivano@usp.br

Otávio Bandeira Lamônica Freire

Doutor

Ciências da Comunicação pela Escola de Comunicações e Artes da Universidade de São Paulo (ECA-USP) orfreire@usp.br

Resumo:

Objetivo do estudo: este artigo tem como objetivo principal compreender a produção científica que aborda a relação das mulheres com o turismo de aventura e ecoturismo, norteando o desenvolvimento sobre o assunto.

Metodologia/abordagem: análise de 43 artigos científicos, encontrados na base de dados SciVerse Scopus®, no período de 1998 até junho de 2020, utilizando como metodologia a bibliometria com auxílio do software IRAMUTEQ®.

Originalidade/relevância: as desigualdades de gênero são obstáculos para o desenvolvimento de uma sociedade mais justa, entretanto esse problema ainda é refletido até mesmo nos segmentos considerados mais sustentáveis dentro do turismo como o de aventura e do ecoturismo. Pensando nessa problemática, percebeu-se a importância de compreender a relação das mulheres com esses segmentos.

Principais resultados: foi possível perceber que o tema é ascendente, com a maioria dos estudos utilizando abordagem qualitativa e tendo sido publicados em diversos periódicos internacionais de impacto. Os estudos encontrados identificam benefícios e barreiras a serem ultrapassadas dentro desses segmentos para as mulheres. Outro resultado foi a evidência do agroturismo, que surgiu em vários estudos. Os assuntos de igualdade de gênero, papel da mulher e a experiência das mulheres têm destaque no tema.

Contribuições teóricas/metodológicas: apresenta uma análise completa das produções científicas sobre a relação das mulheres com o turismo de aventura e o ecoturismo, demonstrando principais aspectos e lacunas, servindo como base para o desenvolvimento do conhecimento na área e contribuindo para uma agenda de estudos futuros.

Palavras-chave: Natureza. Desenvolvimento social. Sexismo. Participação feminina. Feminismo.

\section{Cite como}

American Psychological Association (APA)

Santos, I. S., Borges, A. A., Scrivano, P., \& Freire, O. B. L. (2022, jan./abr.). O que sabemos sobre a relação das mulheres com o turismo de aventura e ecoturismo? PODIUM Sport, Leisure and Tourism Review, São Paulo, 11(1), 175-209. https://doi.org/10.5585/podium.v11i1.19545. 


\title{
WHAT DO WE KNOW ABOUT THE RELATIONSHIP OF WOMEN WITH ADVENTURE TOURISM AND ECOTOURISM?
}

\begin{abstract}
:
Objective of the study: this articles main objective is to understand the scientific production that addresses the relationship of women with adventure tourism and ecotourism, guiding the development on the subject.

Methodology/approach: analysis of 43 scientific articles, found in the SciVerse Scopus ${ }^{\circledR}$ database, from 1998 to June 2020, using bibliometrics as a methodology with the aid of the IRAMUTEQ ${ }^{\circledR}$ software.

Originality/relevance: gender inequalities are obstacles to the development of a more just society, however this problem is still reflected even in the segments considered to be more sustainable within tourism, such as adventure and ecotourism. With that problem in mind, the importance of understanding the relationship of women with these segments became clear.

Main results: it was possible to perceive that the theme is ascending, with the majority of studies using a qualitative approach and having been published in several international impact journals. The found studies identify benefits and barriers, still to be overcome, within these segments for women. Another result was the relevance of agritourism, which appeared in several studies. The issues of gender equality, the role of women and the experience of women are highlighted in the theme.

Theoretical/methodological contributions: presents a complete analysis of scientific productions on the relationship of women with adventure tourism and ecotourism, demonstrating main aspects and gaps, serving as a basis for the development of knowledge in the area and contributing to an agenda for future studies.
\end{abstract}

Keywords: Nature. Social development. Sexism. Female participation. Feminism.

\section{¿LO QUE SABEMOS SOBRE LA RELACIÓN DE MUJERES CON TURISMO DE AVENTURA Y ECOTURISMO?}

\section{Resumén:}

Objetivo del estudio: este artículo tiene como objetivo principal comprender la producción científica que aborda la relación de las mujeres con el turismo de aventura y el ecoturístico, orientando el desarrollo en el tema.

Metodología/enfoque: análisis de 43 artículos científicos, que fueron encontrados en la base de datos SciVerse Scopus®, desde 1998 hasta junio de 2020, utilizando la bibliometría como metodología con la ayuda del software IRAMUTEQ®.

Originalidad/relevancia: las desigualdades de género son obstáculos para el desarrollo de una sociedad más justa, sin embargo este problema aún se refleja incluso en los segmentos considerados más sostenibles dentro del turismo, como la aventura y el ecoturismo. Al pensar en este problema, se percató de la importancia de comprender la relación de las mujeres con estos segmentos.

Principales resultados: se pudo percibir que la temática es ascendente, teniendo la mayoría de los estudios con enfoque cualitativo y han sido publicados en varias revistas internacionales de impacto. Los estudios encontrados identifican beneficios y barreras que deben superarse dentro de estos segmentos para las mujeres. Otro resultado fue la evidencia de agroturismo, que apareció en varios estudios. En el tema se destacan las cuestiones de la igualdad de género, el papel de la mujer y la experiencia de la mujer.

Contribuciones teóricas/metodológicas: el artículo presenta un análisis completo de las producciones científicas sobre la relación de la mujer con el turismo de aventura y el ecoturismo, demostrando los principales aspectos y brechas, sirviendo de base para el desarrollo del conocimiento en el área y contribuyendo a una agenda de estudios futuros.

Palabras clave: Naturaleza. Desarrollo social. Sexismo. Participación feminina. Feminismo. 


\section{Introdução}

Os segmentos de turismo de aventura e ecoturismo estão por diversas vezes associados, ambos contendo características bastante distintas do turismo de massa, por exemplo. Tais segmentos visam a um desenvolvimento mais sustentável, apresentam maior preocupação com a preservação da natureza do destino e maior responsabilidade social, bem como valorizam a economia local (World Tourism Organization, 2014).

Apesar da preocupação social e ambiental desses dois segmentos, por vezes seguem refletindo alguns problemas da sociedade como o sexismo, ou seja, o conjunto de atitudes discriminatórias que busca estabelecer o papel social que cada gênero deve exercer. Assim, podendo ser hostil, em que a mulher é colocada como inferior ao homem, ou benevolente, em que a mulher é tida como frágil e carente de proteção (Glick \& Fiske, 1996).

A ocorrência desse problema tem destaque dentro do segmento de aventura, talvez pelo fato do segmento ainda ter maior representatividade masculina, como também o estereótipo ideal a figura do homem corajoso e destemido (Mendoza, 2020). Tal estereótipo estaria supostamente mais próximo das características necessárias para enfrentamento de situações e problemas ligados ao ambiente natural do que às mulheres. O que se deve à sociedade, por ainda erroneamente, conceber a figura feminina como um ser frágil (Schwartz, Pereira, Figueiredo, Christofoletti, \& Dias, 2016).

Desse modo, costuma-se colocar a mulher no seu dito papel tradicional, normalmente mais ligado ao ecoturismo e principalmente na segmentação do agroturismo, como por exemplo, o de conservação da natureza (Nichols, O’Brien, \& Heimlich, 1998), trabalhos com artesanato (A. M. Johnson, 1999) e culinária (Hirtenfelder, 2016). Isso incorre na identificação das mulheres com atividades domésticas e "invisíveis", que acaba a explorar os serviços femininos e aumentar a desigualdade de gênero, por meio da divisão sexual de trabalho.

A partir disso, é possível notar que o turismo de aventura e o ecoturismo trazem características distintas, mas ambas associadas de alguma forma ao sexismo. Nesse sentido, atualmente são presenciados fortes esforços para que ocorra uma mudança nessas realidades e percepções. Assim como, o aumento da preocupação de alcançar a igualdade de gênero e o empoderamento feminino, esses inclusive estão previstos dentro dos Objetivos de Desenvolvimento Sustentável (ODS) da Agenda 2030 (United Nations Organization, 2018).

Sendo assim, percebe-se a necessidade de compreender melhor a questão desses segmentos turísticos. Portanto, o presente artigo tem como objetivo contextualizar os estudos 
científicos sobre as mulheres e os segmentos de turismo de aventura e ecoturismo. Além disso, busca compreender a evolução das publicações dos artigos, os principais focos desses trabalhos, as principais conclusões e as lacunas existentes.

\section{Revisão de literatura}

Para Gentry (2007), o ecoturismo é um setor central da indústria do turismo alternativo que engloba o turismo de herança, rural, cultural e de aventura. Já em outras literaturas, é possível encontrar o ecoturismo como parte das atividades soft do turismo de aventura, consideradas mais fáceis e de menores riscos, em contraponto às atividades hard, consideradas mais difíceis e com maiores riscos (World Tourism Organization, 2014). O presente estudo irá adotar essa última classificação, colocando o ecoturismo como um segmento de aventura mais soft.

É importante destacar que a aventura se caracteriza por experiências físicas e sensoriais recreativas que envolvem desafios, podendo proporcionar sensações diversas como liberdade, prazer e superação, a depender da expectativa, do envolvimento e da experiência do turista, além do nível de dificuldade de cada atividade (Marinho, 2006; Sampaio \& Bahia, 2007). Ademais, a aventura pode ocorrer em meios urbanos, embora, seja normalmente mais relacionada com cenários de natureza "selvagem", costumeiramente dominados pela figura masculina. Segundo Mendoza (2020), a indústria desses segmentos facilitou a ascensão de um sujeito masculino com base em valores corporais fundamentais: fisicalidade robusta, ética conservacionista e narração heroica sobre a natureza selvagem envolvente. Nesse mesmo sentido, pesquisas como a de Jordan \& Gibson (2005), McArthur (1999) e Wilson e\& Little (2005) revelam que geralmente, nesses segmentos, os homens obtêm o controle social da estrutura e até avaliam o que é considerado apropriado ou não para as turistas mulheres.

Apesar desse histórico domínio do sexo masculino, no ano de 2010, já havia estudos que indicavam que essa afirmação estava mudando, devido ao aumento do número de mulheres no turismo de aventura, principalmente na categoria soft, onde elas passaram a ser maioria $(63,2 \%)$. Entretanto, o mesmo não havia ocorrido com a categoria hard (Kane \& Tucker, 2010). Três anos após, em 2013, estudos do mercado de turismo de aventura apontavam que 57\% dos viajantes de aventura eram do sexo masculino e $43 \%$ eram do sexo feminino. Mas no ano seguinte, em 2014, já havia um estudo anual de comércio global, específico para operadores turísticos, o qual refletia que $53 \%$ de seus viajantes eram do sexo feminino e $47 \%$ deles do sexo 
masculino (World Tourism Organization, 2014). Assim, percebeu-se que, no âmbito internacional, as mulheres estavam passando a ocupar mais os espaços nesses segmentos; primeiro, tornaram-se maioria no ecoturismo e, posteriormente, no turismo de aventura em geral.

No que se refere ao Brasil, os últimos estudos realizados ainda apontavam o ecoturismo e o turismo de aventura como segmentos com um público majoritariamente masculino (Brasil, 2010). Inclusive, há pesquisas atuais que buscam o porquê de as mulheres brasileiras viajarem menos que os homens, apesar de serem maioria no país. Uma das questões identificadas foi o medo de viajar sozinhas por serem mulheres, tendo a violência como principal ameaça (Voopter, 2018).

Além dessa barreira cultural do medo, é possível citar outras como a econômica. Segundo o índice Gender Pay Gap - GPG, da The Organisation for Economic Co-operation \& Development (OECD), nenhum país, no mundo, a mulher ganha mais do que o homem. Entre os países-membros da OCDE a diferença média de salários entre homens e mulheres é de 14\% (OECD, 2019). Essa diferença é ainda maior no Brasil, onde as mulheres recebem 20,5\% menos que os homens (IBGE, 2019).

Acabar com essa desigualdade de gênero, nesse e em diversos outros aspectos, é atualmente um dos Objetivos de Desenvolvimento Sustentável ODS, que coloca o empoderamento feminino como forma de atingir tal objetivo (United Nations Organization, 2018). Assim, o turismo é apontado como um potencial elemento desse empoderamento (Datt e Gailey, 2012).

Ao pesquisar os temas, gênero no turismo, ecoturismo e turismo de aventura, de forma separada, é possível encontrar alguns estudos bibliométricos que já apontam alguns resultados. Cheng et al. (2016) apontam que as áreas de foco com pesquisa em turismo de aventura são experiências em turismo de aventura, planejamento e desenvolvimento de destinos e operadores de turismo de aventura. Quando o tema é ecoturismo Liu \& Li (2020) revelaram que a conservação era o foco principal, a área protegida era o objeto de estudo principal, e o turismo sustentável era o objetivo principal. No entanto, nenhum desses estudos traz resultados que apontam para relação de tais segmentos com o gênero. Por outro lado, Figueroa-Domecq et al. (2015) realizaram uma bibliometria sobre gênero e turismo. Os autores alegam que, apesar de três décadas de estudo e um recente aumento de artigos, a pesquisa de gênero no turismo permanece marginal à investigação do turismo, o que corrobora com o objetivo deste artigo. 
Nesse contexto, é possível identificar a partir desta sucinta revisão que existe um problema de gênero no turismo de aventura e ecoturismo, mas também há modificações que vêm ocorrendo ao longo do tempo, e que essa relação ainda não foi contemplada pelos estudos bibliométricos. Logo, faz-se compreender que nesse tópico há diversos aspectos interessantes a serem analisados, tais como: Será que a produção científica não apresenta estudos interessados por tal temática? O que os estudos, que se relacionam a esses temas, trazem de resultados? Quais são os principais focos e conclusões? Realmente existem lacunas sobre o assunto? Enfim, pretende-se aqui responder a esses questionamentos.

\section{Metodologia}

A metodologia tem uma abordagem qualitativa de cunho exploratório pautado em um estudo bibliométrico. A bibliometria é utilizada para avaliar e monitorar o progresso de determinados temas, procurando cobrir uma ampla gama de leis e metodologias (McBurney e Novak, 2002). Nela é possível a aplicação de técnicas estatísticas básicas ou avançadas aos dados obtidos de estudos publicados anteriormente (Cobo, López-Herrera, Herrera-Viedma, \& Herrera, 2011; McBurney e Novak, 2002). Diante disso, é importante esclarecer que para a realização deste trabalho, utilizamos as técnicas de Estudos de Revisão e Técnicas Relacionais, de acordo com a classificação de Koseoglu et al. (2016).

Dessa forma, foram feitas as buscas em junho de 2020 na base de dados SciVerse Scopus ${ }^{\circledR}$, de propriedade da Editora Elsevier ${ }^{\circledR}$, por meio do periódico da Coordenação de Aperfeiçoamento de Pessoal de Nível Superior (CAPES). A ferramenta, em questão, foi escolhida por agregar o maior banco de dados de resumos e citações da literatura com revisão por pares, oferecendo um panorama abrangente da produção de pesquisas do mundo e disponibilizando ferramentas acessíveis para monitorar, analisar e visualizar estes estudos (Elsevier, 2018).

Dentro dessa base, foi utilizada a função Topic, que realiza a busca nos campos título, resumo e palavras-chave. Nela foram empregadas palavras da seguinte forma: woman OR women OR gender AND "adventure tourism" OR ecotourism. Todas as palavras foram utilizadas no idioma inglês por se tratar de base internacional. Optou-se por excluir a palavra female, pois esta normalmente era ligada a estudos da biologia animal. A pesquisa foi delimitada apenas para artigos científicos. 
Foram encontrados 143 artigos, todos catalogados em uma planilha do Microsoft Excel®, incluindo título, autores, ano, periódico, número de citações, resumo, palavras-chave, país onde foi feito o estudo, grupo pesquisado, tema principal e método utilizado. Após a leitura dos resumos, foram eliminados dezessete artigos que não abordavam de gênero humano e 83 eliminados por apenas citar gênero sem focar nesse tema. Dessa maneira, foram analisados os 43 artigos que tinham como tema principal a questão de gênero e o turismo de aventura e ecoturismo.

Neste estudo de revisão com foco temático (Koseoglu et al., 2016), foram realizadas análises de variáveis selecionadas a partir da leitura integral dos textos, para obtenção de gráficos e quadros com as principais informações dos artigos. Essas informações foram organizadas em variáveis: principais tópicos, conclusões, sugestões futuras das pesquisas, países estudados pelos artigos e metodologias e abordagens utilizadas nos estudos. Também, nesta etapa, foram apresentadas a evolução do número de artigos ao longo dos anos e a distribuição dos artigos, nos periódicos científicos.

Posteriormente, nas técnicas relacionais, foi feita uma análise de citação dos artigos, análise dos principais autores e coautores, um estudo de cocitações e, por fim, uma análise de co-word (Koseoglu et al., 2016). Para o estudo de cocitação, foi feita uma Análise Fatorial Exploratória (AFE) por meio da análise dos componentes principais - técnica amplamente utilizadas em estudos bibliométricos, no campo da administração (Zupic \& Cater, 2015) - sendo útil para descrever a variabilidade compartilhada entre as variáveis medidas e para investigar potenciais fatores latentes subjacentes por meio de variáveis mensuráveis. Assim, é possível fazer a redução de dados para descobrir padrões desconhecidos de relações (Luo et al. 2019), no caso, revelando os fatores compostos pelas cocitações. Nessa etapa, foram utilizados o BibExcel® e o IBM SPSS Statistics 20®, seguindo as recomendações de Hair et al. (1998). Dessa forma, entende-se que os artigos citados são as variáveis analisadas, que formam os componentes, ou seja, os fatores. Essa técnica auxilia no entendimento de novas temáticas e áreas, podendo auxiliar, por exemplo, na identificação de tendências, assim como, na estruturação dos pilares teóricos e metodológicos que fundamentam determinado campo científico (Quevedo-Silva, Santos, Brandão, \& Vils, 2016).

Já a análise de co-word foi feita por meio do software IRAMUTEQ® (Interface de $R$ pour les Analyses Multidimensionnelles de Textes et de Quastionnaires). Com isso, é realizada, nele, análise lexical quantitativa na qual a palavra é considerada como unidade, enquanto fornece sua contextualização por meio de segmentos de texto do corpus textual em análise. 
Assim, foi possível a extração de significado dos artigos analisados (Camargo \& Justo, 2013). Concomitantemente, foram codificados todos os títulos, resumos e palavras-chave, formando assim um corpus textual, sendo utilizados para duas análises diferentes. Logo, ao gerar as estatísticas descritivas, percebe-se que o número de Hápax, ou seja, o número de palavras que foram utilizadas ou registradas apenas uma vez nos textos (Loubère \& Ratinaud, 2014), foi de apenas 12,96\% demonstrando o grau de convergência entre os artigos em questão.

Na primeira etapa, foi feita uma Nuvem de Palavras, onde as estas têm seu tamanho proporcional à sua frequência dentro do corpus textual, nessa parte foram retiradas as palavras utilizadas na busca, para que fosse possível visualizar melhor quais novas palavras-chave estão ligadas ao tema estudado. Na segunda etapa da análise de conteúdo, foi feita a classificação hierárquica descendente (CHD), onde são geradas classes com seus respectivos dicionários de palavras baseadas no corpus textual em questão. Para a criação de um dicionário de palavras, o programa utiliza o teste qui-quadrado $(\chi 2)$, que revela a força associativa entre as palavras e a sua respectiva classe. (Loubère \& Ratinaud, 2014; Souza, Wall, Thuler, Lowen, \& Peres, 2018). O software também gera um documento, chamado Typical Text Segments, onde aparecem as frases que mais representam cada uma das classes geradas e, a partir dele, é possível compreendê-las e nomeá-las.

\section{Resultados e discussões}

Percebe-se que as publicações começaram a emergir em 1998, ou seja, há praticamente 22 anos. Durante esse período, houve um crescimento no número de estudos, principalmente nos últimos anos, demonstrando o aumento de interesse científico pelo tema Gênero relacionado aos segmentos de Turismo de Aventura e Ecoturismo (Figura 1). 
Santos, I. S., Borges, A. A., Scrivano, P., \& Freire, O. B. L. (2022, jan./abr.). O que sabemos sobre a relação das mulheres com o turismo de aventura e ecoturismo?

Figura 1.

Evolução do Número de Publicações de Artigos Científicos com o Tema de Gênero e Turismo de Aventura e Ecoturismo no Período de 1998 a Junho de 2020 da Base de Dados Scopus

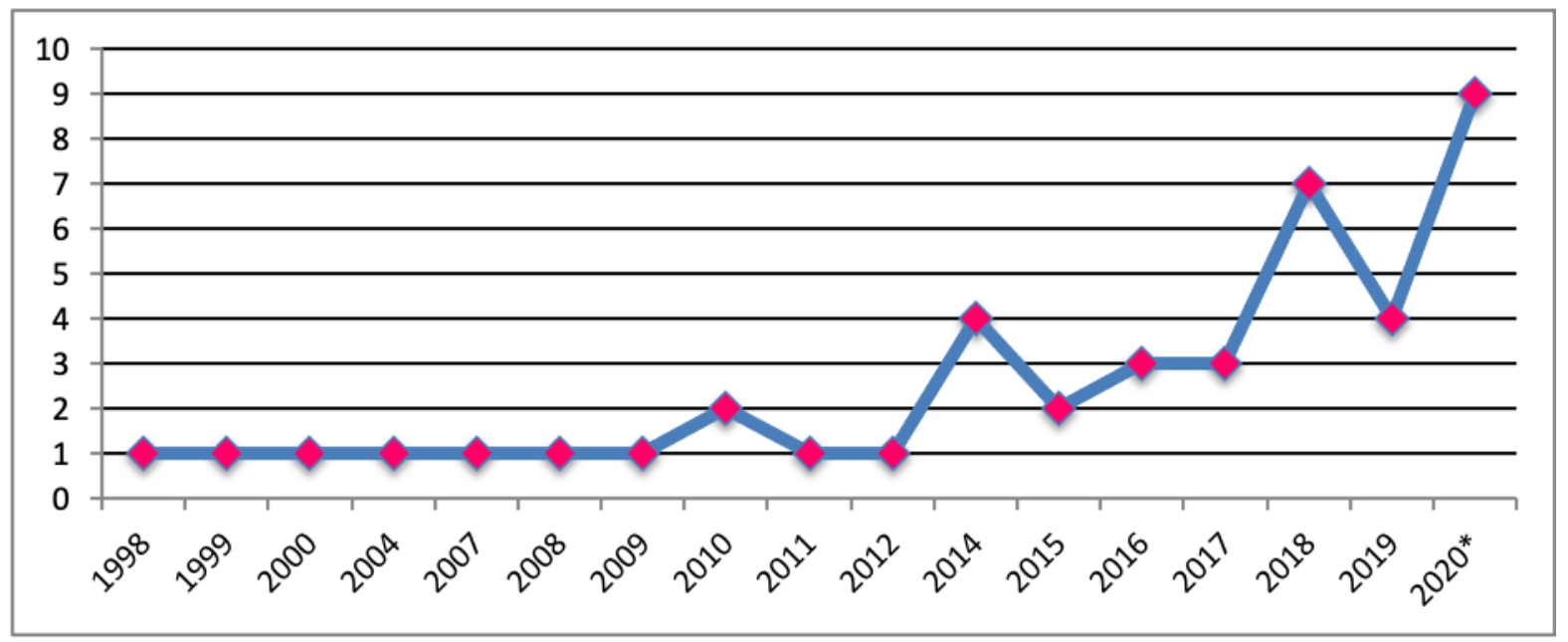

*2020 foi pesquisado apenas até o mês de junho.

Fonte: Elaborada pelos autores (2020).

O aumento da produção científica sobre gênero no turismo de aventura e ecoturismo ocorre em um contexto histórico da quarta onda feminista, que segundo Cochrane (2014) intensificou-se por volta de 2012 (figura 1). Ao longo da história, grupos femininos vêm organizando-se de diferentes maneiras e em vários momentos. Em alguns desses períodos, existem acúmulos de reivindicações e conquistas. Tais períodos são chamados de Ondas Feministas, onde cada uma dessas ondas tem seus próprios momentos históricos relevantes na sociedade e na academia, com determinadas pautas e questões das mulheres que se insurgem e dominam os debates.

Essa Quarta Onda Feminista tem como características a ligação com a tecnologia, com a internet associada às redes sociais como Facebook, Twitter, Instagram, YouTube e Tumblr, assim como blogs utilizados para contestar a misoginia ${ }^{1}$ e outros exemplos de desigualdade de gênero, focando na justiça para as mulheres (Chamberlain, 2017; Cochrane, 2014; Maclaran, 2015; Risman, 2017). Portanto, a questão de gênero se mostra como uma promissora temática de estudo, devido a tendência sociopolítica do presente momento. Acadêmica e cientificamente, o turismo se encontra dentro da área de Ciências Sociais Aplicadas, reafirmando o dever de atender às demandas da sociedade por estudos que coloquem em foco essa discussão de igualdade de gênero.

${ }^{1}$ De acordo com Gomes et al. (2014) rejeição por aquilo que diz respeito ao sexo feminino. 
É interessante, também, lembrar que as publicações do ano de 2020 foram analisadas somente até o mês de junho, por ser a data do levantamento dos dados. Com nove artigos sobre o tema até o levantamento, este ano já pode ser considerado como o período de maior quantidade de artigos envolvendo Gênero e Turismo de Aventura ou Ecoturismo.

Apesar do crescimento, ao comparar com outros temas estudados no turismo, esse número de publicação ainda é baixo, visto que ao realizar uma busca na mesma base de dados SciVerse Scopus ${ }^{\circledR}$ referente a assuntos do turismo, é possível encontrar um total de 7015 artigos, apenas no ano de 2019, desse montante, apenas nove tinham como foco a questão de gênero e desses somente quatro se referiam a questão de gênero ligada ecoturismo ou turismo de aventura (Scopus, 2020).

Além disso, foram analisados o h-index e o Journal Citation Reports (JCR) dos periódicos onde foram publicados os artigos selecionados. O primeiro foi conferido pelo Scimago Journal e Country Rank (2020) e o segundo na página oficial de cada periódico, o resultado encontra-se no Quadro 1.

\section{Quadro 1.}

Índices H Index e JCR dos Periódicos onde foram publicados os artigos científicos sobre Gênero e

Turismo de Aventura e Ecoturismo período de 1998 a 2020 na base de dados Scopus

\begin{tabular}{|l|r|r|r|}
\hline \multicolumn{1}{|c|}{ Periódicos } & $\mathrm{N}^{\circ}$ de Artigos & H Index & \multicolumn{1}{|c|}{ JCR } \\
\hline Annals of Tourism Research & 2 & 158 & 5.91 \\
\hline Journal of Travel Research & 1 & 122 & 7.03 \\
\hline Environment and Planning A & 1 & 121 & 3.03 \\
\hline Journal of Sustainable Tourism & 5 & 93 & 3.99 \\
\hline Society and Natural Resources & 1 & 82 & 1.81 \\
\hline Journal of Forestry & 1 & 70 & 2.34 \\
\hline Sustainability (Switzerland) & 2 & 68 & 2.58 \\
\hline Rural Sociology & 1 & 63 & 2.49 \\
\hline Leisure Studies & 2 & 61 & 1.57 \\
\hline Tourism Geographies & 1 & 56 & 3.16 \\
\hline Environment, Development and Sustainability & 1 & 52 & 2.20 \\
\hline Tourism Recreation Research & 2 & 41 & $\mathrm{~N} / \mathrm{C}$ \\
\hline Journal of Sport and Tourism & 2 & 40 & $\mathrm{~N} / \mathrm{C}$ \\
\hline Ecology of Food and Nutrition & 1 & 34 & 1.07 \\
\hline Earth System Dynamics & 1 & 33 & 3.87 \\
\hline Asia Pacific Journal of Tourism Research & 1 & 33 & 2.02 \\
\hline Journal of Ecotourism & 1 & 33 & $\mathrm{~N} / \mathrm{C}$ \\
\hline Tourism Management Perspectives & 1 & 33 & 3.65 \\
\hline
\end{tabular}


Santos, I. S., Borges, A. A., Scrivano, P., \& Freire, O. B. L. (2022, jan./abr.). O que sabemos sobre a relação das mulheres com o turismo de aventura e ecoturismo?

\begin{tabular}{|c|c|c|c|}
\hline Periódicos & $\mathrm{N}^{\circ}$ de Artigos & H Index & $J C R$ \\
\hline Journal of Food, Agriculture and Environment & 1 & 32 & $\mathrm{~N} / \mathrm{C}$ \\
\hline Bulletin of Latin American Research & 2 & 31 & 0.59 \\
\hline Tourism Planning and Development & 1 & 27 & $\mathrm{~N} / \mathrm{C}$ \\
\hline African Studies & 1 & 24 & 0.35 \\
\hline Tourism & 1 & 20 & $\mathrm{~N} / \mathrm{C}$ \\
\hline Annals of Leisure Research & 1 & 19 & $\mathrm{~N} / \mathrm{C}$ \\
\hline Journal of China Tourism Research & 1 & 18 & $\mathrm{~N} / \mathrm{C}$ \\
\hline International Journal of Scientific and Technology Research & 1 & 15 & $\mathrm{~N} / \mathrm{C}$ \\
\hline GeoJournal & 1 & 9 & $\mathrm{~N} / \mathrm{C}$ \\
\hline Transforming Anthropology & 1 & 8 & $\mathrm{~N} / \mathrm{C}$ \\
\hline Entrepreneurial Executive & 1 & 7 & $\mathrm{~N} / \mathrm{C}$ \\
\hline Caribbean Geography & 1 & 7 & $\mathrm{~N} / \mathrm{C}$ \\
\hline Cuadernos de Turismo & 1 & 7 & $\mathrm{~N} / \mathrm{C}$ \\
\hline African Journal of Hospitality, Tourism and Leisure & 2 & 6 & $\mathrm{~N} / \mathrm{C}$ \\
\hline
\end{tabular}

Fonte: Elaborada pelos autores (2020).

Não há uma concentração de publicação em uma ou poucas revistas, com exceção do Journal of Sustainable Tourism, com cinco estudos. Todos os outros possuem apenas um ou dois artigos publicados. Trata-se de um dado relevante, pois demonstra a diversidade de periódicos que estão abordando o tema. Os artigos estão distribuídos em 32 revistas diferentes, a maioria ligada ao turismo, geografia e planejamento. Mais da metade dos periódicos continham JCR, sendo grande parte desses com alto fator de impacto, o que demonstra que o tema está configurando com estudos qualificados.

Além dos índices, também foram identificados os tópicos principais de cada artigo, por meio da leitura do título, do resumo e das palavras-chave. Dessa forma, foi possível perceber que o Empoderamento Feminino relacionado ao Ecoturismo foi o mais recorrente, sendo o assunto principal em dezesseis artigos, seguido por sete artigos sobre Ecoturismo relacionado ao Papel da Mulher, demonstrando que grande parte das pesquisas se refere ao Ecoturismo em geral, sem focar no Turismo de Aventura (Figura 2). 
Santos, I. S., Borges, A. A., Scrivano, P., \& Freire, O. B. L. (2022, jan./abr.). O que sabemos sobre a relação das mulheres com o turismo de aventura e ecoturismo?

Figura 2.

Principais Tópicos Identificados na Análise dos Artigos Científicos Sobre Gênero e Turismo de Aventura e Ecoturismo no Período de 1998 a Junho de 2020 da Base de Dados Scopus

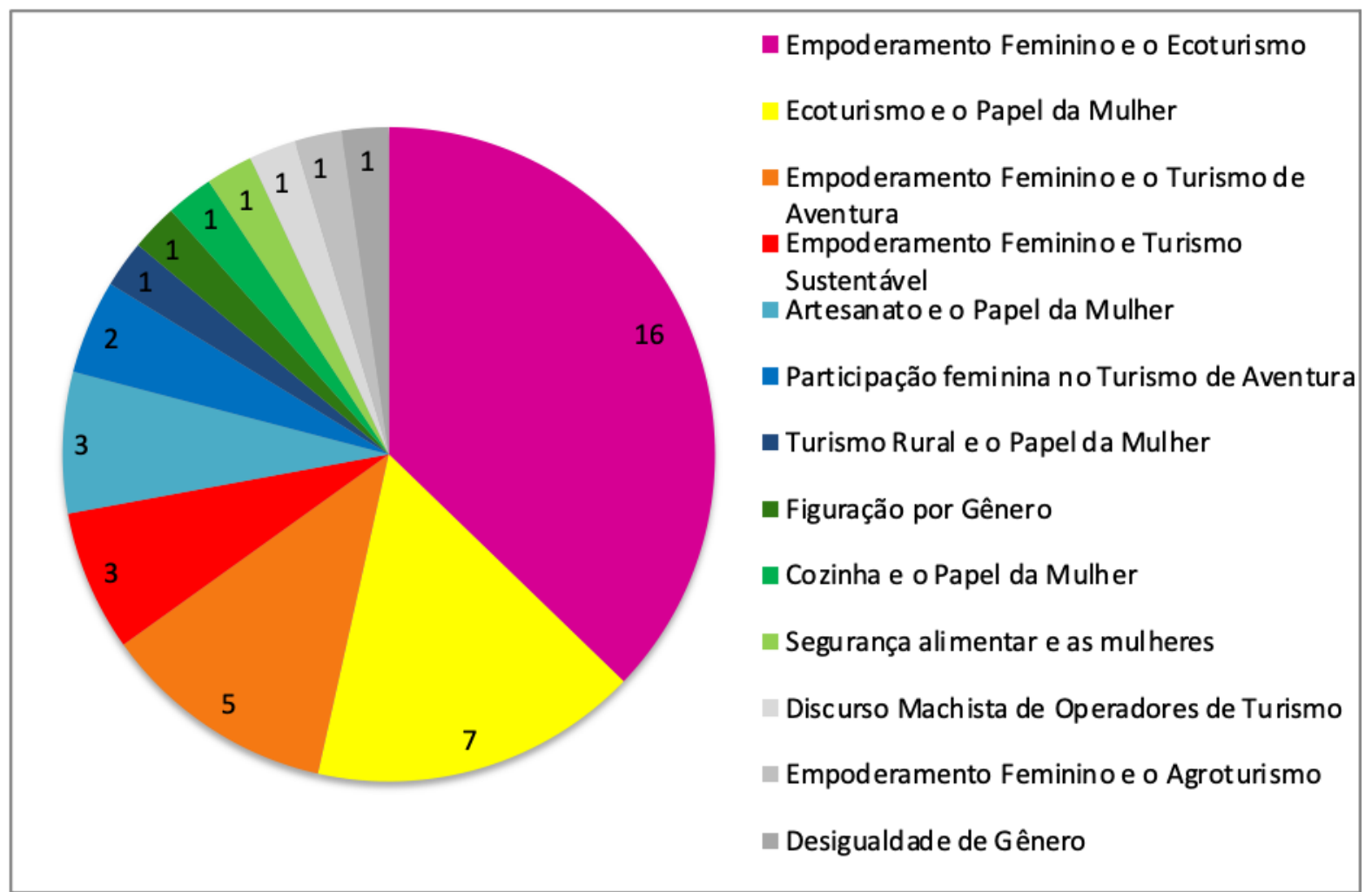

Fonte: Elaborada pelos autores (2020).

O turismo de aventura apareceu relacionado ao empoderamento com uma frequência de cinco artigos e relacionado à participação feminina em dois, ou seja, dos 43 artigos analisados, apenas sete abordavam especificamente atividades de aventura na natureza como montanhismo (3), trekking (1) e aventuras em geral (3). Os outros artigos não utilizavam a palavra aventura como parte do principal tópico.

Outro fator percebido, durante a análise, foi que a maioria das pesquisas é feita com as residentes dos destinos turísticos, totalizando 36 artigos. Enquanto isso, apenas cinco estudos trabalharam exclusivamente com turistas e dois abrangiam turistas e trabalhadoras de operadoras turísticas ao mesmo tempo. Com isso, percebe-se uma ênfase no empoderamento, mas com um viés de desenvolvimento de dentro para fora, sendo interessante notar a falta de estudos com a percepção das consumidoras desse turismo (Doran, Schofield, \& Low, 2020). Tais estudos são, inclusive, importantes do ponto de vista econômico, já que são eles que irão abordar o potencial competitivo dos lugares, trazendo-lhes investimento e beneficiando-os, 
assim como as residentes. Logo, é importante que as pesquisas estudem ambos os lados da moeda, residentes e consumidoras.

Além dessa tendência quanto ao grupo estudado, também se notou uma preferência pelo uso de metodologias com abordagens qualitativas, representando mais da metade do total de artigos analisados, sendo que 28 estudos realizaram apenas abordagens qualitativas, 10 fizeram uso somente de abordagens quantitativas e 05 utilizaram ambas. Essa constatação vai ao encontro das análises de Vizcaíno, Serrano, Cruz e Pastor (2016) e Mejía Vázquez, Serrano Barquín, Osorio González e Favila Cisneros (2019), as quais realizaram uma bibliometria dos artigos de idioma português e espanhol, referentes ao tema gênero e turismo. Pode-se perceber, então, que existe uma preferência ibero-americana e internacional por esse tipo de abordagem dentro dessa área. As pesquisas de abordagem qualitativa são de característica exploratória, portanto não são de caráter conclusivo, havendo a falta de estudos quantitativos e de testes de hipóteses. Grande parte desses estudos estão se limitando a explorar as situações em profundidade. Dessa forma, seria interessante que a academia olhasse os estudos realizados até aqui, procurando entender quais deles, em conjunto ou isoladamente, já estabelecem padrões, para que se possa desenvolver e testar hipóteses, fazendo com que o campo de pesquisa de gênero e turismo amadureça do ponto de vista científico.

Ademais, foram catalogados 35 países diferentes, os quais foram foco de estudo dos artigos analisados, demonstrando ampla variedade, do ponto de vista do relevo, clima e demais características geográficas. Nepal, país da Ásia Meridional, destacou-se com quatro ocorrências, por ser um destino de turismo de aventura devido a Cordilheira do Himalaia, onde fica o Monte Everest (Quadro 2). 


\section{Quadro 2.}

Países Estudados nos Artigos Científicos Sobre Gênero e Turismo de Aventura e

Ecoturismo no Período de 1998 a Junho de 2020

\begin{tabular}{|l|r|l|r|}
\hline \multicolumn{1}{|c|}{ País } & \multicolumn{1}{c|}{ Artigos } & \multicolumn{1}{c|}{ País } & \multicolumn{1}{c|}{ Artigos } \\
\hline Nepal & 4 & Turquia & 1 \\
\hline Botsuana & 3 & Vietnã & 1 \\
\hline Gana & 3 & Camarões & 1 \\
\hline México & 2 & Albânia & 1 \\
\hline Belize & 2 & China & 1 \\
\hline Nova Zelândia & 2 & Brasil & 1 \\
\hline África do sul & 2 & Tanzânia & 1 \\
\hline Indonésia & 2 & Iran & 1 \\
\hline Japão & 1 & Costa Rica & 1 \\
\hline Peru & 1 & Jamaica & 1 \\
\hline Argentina & 1 & Índia & 35 \\
\hline Fiji & 1 & \multicolumn{2}{|c|}{ Total } \\
\hline
\end{tabular}

Fonte: Elaborado pelos autores (2020).

No entanto, percebe-se uma concentração de estudos relacionados ao gênero e turismo de aventura e ecoturismo em países asiáticos e africanos. Isso pode ser explicado por dois fatores: o primeiro é o que estes destinos contam com diversos atrativos naturais, daí a ligação com os segmentos de ecoturismo e aventura. Já o segundo é que estes continentes enfrentam maiores problemas com a questão da desigualdade de gênero, o que chama atenção das pesquisadoras e pesquisadores para escrever sobre o tema.

A Thomson Reuters Foundation (2018) consultou 550 especialistas sobre a situação das mulheres em todos os 193 países-membros da Organização das Nações Unidas (agen), constatando que os piores locais para as mulheres viverem estavam inseridos nos continentes africano e asiático. Nesse sentido, também se percebe que as pesquisas estão focadas principalmente em países periféricos, havendo poucos estudos em lugares considerados desenvolvidos. Assim, é interessante destacar que futuros estudos foquem também em outros destinos.

É importante ressaltar que para compreender melhor as contribuições dos trabalhos analisados, também foi realizada uma leitura mais aprofundada de cada artigo. E assim, foram identificadas as principais conclusões, sugestões de estudos futuros e a quantidade de citações dos artigos, para sabermos seu impacto na comunidade acadêmica. Os resultados dessa análise foram dispostos no Quadro 3 a seguir. 
Santos, I. S., Borges, A. A., Scrivano, P., \& Freire, O. B. L. (2022, jan./abr.). O que sabemos sobre a relação das mulheres com o turismo de aventura e ecoturismo?

Quadro 3.

Principais Conclusões, Sugestões e Citações Identificadas nos Artigos Científicos Sobre Gênero e

Turismo de Aventura e Ecoturismo no Período de 1998 a Junho de 2020 da Base de Dados Scopus

\begin{tabular}{|c|c|c|c|}
\hline Autoras & Conclusões & Sugestões para estudos futuros & Citações \\
\hline $\begin{array}{l}\text { (Nichols et al., } \\
\text { 1998) }\end{array}$ & $\begin{array}{l}\text { Mulheres são responsáveis pela conservação da } \\
\text { floresta e fazem a diferença. }\end{array}$ & $\begin{array}{l}\text { Desenvolver estudos para planos } \\
\text { e programas de conservação } \\
\text { sustentável. }\end{array}$ & 0 \\
\hline $\begin{array}{l}\text { (A. M. Johnson, } \\
\text { 1999) }\end{array}$ & Turismo influenciou as tradições do artesanato. & Inexistente. & 0 \\
\hline $\begin{array}{l}\text { (Scheyvens, } \\
\text { 2000) }\end{array}$ & $\begin{array}{|lll|}\begin{array}{l}\text { Ecoturismo impacta positivamente no } \\
\text { empoderamento. }\end{array} & \\
\end{array}$ & $\begin{array}{l}\text { Encontrar meios de facilitar o } \\
\text { empoderamento por agências. }\end{array}$ & 93 \\
\hline $\begin{array}{l}\text { (Swain \& Swain, } \\
\text { 2004) }\end{array}$ & \begin{tabular}{|lrr}
$\begin{array}{l}\text { Ecofeminismo impacta } \\
\text { ecoturismo. }\end{array}$ & positivamente no \\
\end{tabular} & Inexistente. & 12 \\
\hline (Gentry, 2007) & $\begin{array}{l}\text { Aponta exploração do trabalho das mulheres, } \\
\text { mas o emprego parece oferecer oportunidades } \\
\text { para desafiar a norma. }\end{array}$ & $\begin{array}{l}\text { Analisar o emprego no turismo de } \\
\text { massa. }\end{array}$ & 92 \\
\hline $\begin{array}{l}\text { (Besio, } \\
\text { Johnston, \& } \\
\text { Longhurst, } \\
2008)\end{array}$ & $\begin{array}{l}\text { Discurso de sexualidade promíscua e } \\
\text { maternidade trabalham efetivamente para } \\
\text { vender um produto turístico }\end{array}$ & Inexistente. & 29 \\
\hline $\begin{array}{l}\text { (Cudmore, } \\
\text { Troshani, \& } \\
\text { McCoy, 2009) }\end{array}$ & $\begin{array}{l}\text { O turismo incentiva o empreendedorismo } \\
\text { feminino de maneira a manter alguma } \\
\text { consistência com o papel tradicional das } \\
\text { mulheres. }\end{array}$ & Inexistente. & 1 \\
\hline (Myers, 2010) & $\begin{array}{l}\text { Participação no turismo de aventura trouxe } \\
\text { benefícios como sentimento de conquista, } \\
\text { orgulho e maior confiança das mulheres. }\end{array}$ & $\begin{array}{l}\text { Pesquisas aprofundadas sobre os } \\
\text { benefícios para as mulheres na } \\
\text { participação do turismo de } \\
\text { aventura }\end{array}$ & 22 \\
\hline $\begin{array}{l}\text { (Schellhorn, } \\
\text { 2010) }\end{array}$ & $\begin{array}{l}\text { As mulheres têm mais dificuldade para acessar } \\
\text { as novas oportunidades de desenvolvimento que } \\
\text { o turismo oferece. }\end{array}$ & Inexistente. & 69 \\
\hline (Walter, 2011) & $\begin{array}{l}\text { Em nenhum dos casos houve muito } \\
\text { engajamento sustentado com questões de gênero } \\
\text { em teorização ou pesquisa. }\end{array}$ & $\begin{array}{l}\text { Pesquisas em ecoturismo com a } \\
\text { questão de gênero como um } \\
\text { elemento analítico. }\end{array}$ & 20 \\
\hline $\begin{array}{l}\text { (Külekçi, Sezen, } \\
\text { \& Bulut, 2012) }\end{array}$ & $\begin{array}{l}\text { As mulheres rurais são um recurso humano } \\
\text { importante para o desenvolvimento de sua } \\
\text { região e do país, deixando seu ponto de vista } \\
\text { habitual e tradicional. }\end{array}$ & Inexistente. & 2 \\
\hline $\begin{array}{l}\text { (Tran \& Walter, } \\
\text { 2014) }\end{array}$ & $\begin{array}{l}\text { Ecoturismo impacta positivamente no } \\
\text { empoderamento, divisão do trabalho mais } \\
\text { equitativa, aumento de renda, autoconfiança e } \\
\text { envolvimento da comunidade e novos papéis de } \\
\text { liderança para as mulheres. Mas, desigualdades } \\
\text { de classes e violência contra as mulheres } \\
\text { permaneceram se destacando. }\end{array}$ & $\begin{array}{l}\text { Pesquisas para entender as } \\
\text { mudanças nos papéis de gênero } \\
\text { em um projeto de ecoturismo } \\
\text { baseado na comunidade. }\end{array}$ & 59 \\
\hline $\begin{array}{l}\text { (Medeiros, } \\
\text { 2014) }\end{array}$ & $\begin{array}{l}\text { A dissolução do casamento representa o relato } \\
\text { de uma barganha emergente entre mulheres e } \\
\text { homens. }\end{array}$ & Inexistente. & 1 \\
\hline $\begin{array}{l}\text { (Díaz-Carrión, } \\
\text { 2014) }\end{array}$ & $\begin{array}{l}\text { As principais estratégias das mulheres estão } \\
\text { focadas na gestão de espaços e tempo para } \\
\text { reduzir o papel âncora do trabalho doméstico. }\end{array}$ & Inexistente. & 6 \\
\hline
\end{tabular}




\begin{tabular}{|c|c|c|c|}
\hline Autoras & Conclusões & Sugestões para estudos futuros & Citações \\
\hline $\begin{array}{l}\text { (K. C, \& Thapa } \\
\text { Parajuli, 2014) }\end{array}$ & $\begin{array}{llll}\text { Existe necessidade de conscientização } & \text { e } \\
\text { educação relacionadas ao turismo } & \text { e } \\
\text { empoderamento de gênero das mulheres. } & \end{array}$ & Inexistente. & 18 \\
\hline $\begin{array}{l}\text { (Ogra \& Badola, } \\
\text { 2015) }\end{array}$ & $\begin{array}{l}\text { Existe a necessidade de priorizar o } \\
\text { desenvolvimento de ativos das mulheres para } \\
\text { ajudar a promover a sua capacidade de } \\
\text { adaptação em várias escalas. }\end{array}$ & $\begin{array}{l}\text { Pesquisas para apoiar a justiça de } \\
\text { gênero. }\end{array}$ & 14 \\
\hline $\begin{array}{l}\text { (Ferguson \& } \\
\text { Alarcón, 2015) }\end{array}$ & $\begin{array}{l}\text { Existe a necessidade de fazer um trabalho para } \\
\text { que o gênero seja integrado à teoria e prática do } \\
\text { turismo sustentável. }\end{array}$ & $\begin{array}{l}\text { Abrir um debate sobre como a } \\
\text { igualdade de gênero pode ser } \\
\text { incorporada na política e na } \\
\text { prática do turismo sustentável }\end{array}$ & 38 \\
\hline (Doran, 2016) & $\begin{array}{l}\text { Restrições, negociações e benefícios podem ser } \\
\text { experimentados no turismo de aventura por uma } \\
\text { mulher e podem ser usados como veículo para o } \\
\text { empoderamento. }\end{array}$ & $\begin{array}{l}\text { Mais estudos que possam } \\
\text { aprofundar a compreensão da } \\
\text { jornada de turismo de aventura } \\
\text { das mulheres. }\end{array}$ & 23 \\
\hline $\begin{array}{l}\text { (Hirtenfelder, } \\
\text { 2016) }\end{array}$ & $\begin{array}{l}\text { As mulheres têm menos condições de } \\
\text { diversificar as oportunidades de emprego } \\
\text { turístico disponíveis. }\end{array}$ & Inexistente. & \\
\hline $\begin{array}{l}\text { (Lenao } \& \\
\text { Basupi, 2016) }\end{array}$ & $\begin{array}{l}\text { Faltam políticas públicas para promover o } \\
\text { empoderamento feminino no desenvolvimento } \\
\text { do ecoturismo. }\end{array}$ & Inexistente. & 19 \\
\hline $\begin{array}{l}\text { (Boley, Ayscue, } \\
\text { Maruyama, \& } \\
\text { Woosnam, } \\
\text { 2017) }\end{array}$ & $\begin{array}{l}\text { A diferença do empoderamento de gênero no } \\
\text { turismo não é um fenômeno universal. }\end{array}$ & $\begin{array}{l}\text { Pesquisas para entender melhor as } \\
\text { histórias de sucesso do } \\
\text { empoderamento. }\end{array}$ & 25 \\
\hline $\begin{array}{l}\text { (Hirtenfelder, } \\
\text { 2017) }\end{array}$ & $\begin{array}{l}\text { O ecoturismo, no acampamento em questão, } \\
\text { pouco altera o comportamento dos residentes. }\end{array}$ & Inexistente. & 2 \\
\hline $\begin{array}{l}\text { (Movono \& } \\
\text { Dahles, 2017) }\end{array}$ & $\begin{array}{l}\text { Ecoturismo impacta positivamente no } \\
\text { empoderamento, as mulheres locais atingiram } \\
\text { não apenas o empoderamento econômico, mas } \\
\text { também psicológico, social e político }\end{array}$ & Inexistente. & 28 \\
\hline $\begin{array}{l}\text { (Hidalgo, Elia, } \\
\text { \& Harris, 2018) }\end{array}$ & $\begin{array}{l}\text { O capital social ajuda a empoderar os } \\
\text { indivíduos. }\end{array}$ & $\begin{array}{l}\text { Pesquisas em diferentes } \\
\text { contextos, com objetivo de } \\
\text { promover a equidade e a inclusão } \\
\text { social nas comunidades baseada } \\
\text { em ecoturismo. }\end{array}$ & 9 \\
\hline $\begin{array}{l}\text { (Zeng, Zhou, \& } \\
\text { Zhong, 2018) }\end{array}$ & $\begin{array}{l}\text { Ecoturismo impacta positivamente no } \\
\text { empoderamento, mulheres locais têm cada vez } \\
\text { mais oportunidades de participar de atividades } \\
\text { públicas, e suas vozes estão gradualmente } \\
\text { recebendo maior atenção pelas sociedades } \\
\text { tradicionais. }\end{array}$ & $\begin{array}{l}\text { Mais pesquisas poderiam abordar } \\
\text { a questão de como melhorar a } \\
\text { estrutura de rede social das } \\
\text { moradoras. }\end{array}$ & 1 \\
\hline $\begin{array}{l}\text { (Doran, } \\
\text { Schofield, \& } \\
\text { Low, 2018) }\end{array}$ & $\begin{array}{l}\text { Identifica restrições intrapessoais, interpessoais, } \\
\text { estruturais e familiares para participação das } \\
\text { mulheres no montanhismo. }\end{array}$ & $\begin{array}{l}\text { Identificar com mais detalhes } \\
\text { outras barreiras de restrições à } \\
\text { participação feminina no } \\
\text { montanhismo. }\end{array}$ & 9 \\
\hline $\begin{array}{l}\text { (Ntanjana, } \\
\text { Maleka, } \\
\text { Tshipala, \& du } \\
\text { Plessis, 2018) }\end{array}$ & $\begin{array}{l}\text { As condições de emprego dos funcionários do } \\
\text { turismo de aventura em Gauteng não diferem } \\
\text { entre homens e mulheres. }\end{array}$ & $\begin{array}{l}\text { Analisar o que essas empresas } \\
\text { estão fazendo de maneira } \\
\text { diferente do restante do setor. }\end{array}$ & 2 \\
\hline $\begin{array}{l}\text { (Panta \& Thapa, } \\
\text { 2018) }\end{array}$ & $\begin{array}{l}\text { Ecoturismo impacta positivamente no } \\
\text { empoderamento, empreendedoras obtiveram } \\
\text { vários benefícios em nível individual, como } \\
\text { autoconfiança e habilidades pessoais, maior } \\
\text { acesso a renda em dinheiro e papel na tomada de } \\
\text { decisões na família. }\end{array}$ & $\begin{array}{l}\text { Analisar as empreendedoras } \\
\text { solteiras também. }\end{array}$ & 26 \\
\hline
\end{tabular}




\begin{tabular}{|c|c|c|c|}
\hline Autoras & Conclusões & Sugestões para estudos futuros & Citações \\
\hline $\begin{array}{l}\text { (Hidalgo, Elia, } \\
\text { Kozak, } \\
\text { Harshaw, \& } \\
\text { Tindall, 2018) }\end{array}$ & $\begin{array}{l}\text { Residentes com maior acesso ao capital social } \\
\text { relatam maiores níveis de empoderamento, } \\
\text { mulheres ainda aparecem como menos } \\
\text { capacitadas para tomadas de decisões. }\end{array}$ & Inexistente. & 7 \\
\hline $\begin{array}{l}\text { (Kamat \& Woo } \\
\text { Kinshella, 2018) }\end{array}$ & \begin{tabular}{|l}
$\begin{array}{l}\text { Projetos de ecoturismo contribuem para } \\
\text { segurança alimentar. }\end{array}$ \\
\end{tabular} & Inexistente. & 6 \\
\hline $\begin{array}{l}\text { (Arroyo, } \\
\text { Barbieri, } \\
\text { Sotomayor, \& } \\
\text { Knollenberg, } \\
\text { 2019) }\end{array}$ & $\begin{array}{l}\text { Agroturismo impacta positivamente no } \\
\text { empoderamento, nas dimensões psicológicas, } \\
\text { sociais, políticas e econômicas. }\end{array}$ & $\begin{array}{l}\text { Pesquisas sobre as mudanças na } \\
\text { dinâmica de gênero provocadas } \\
\text { pela participação das mulheres no } \\
\text { agroturismo. }\end{array}$ & 9 \\
\hline $\begin{array}{l}\text { (Kimengsi, } \\
\text { Kechia, Azibo, } \\
\text { Pretzsch, \& } \\
\text { Kwei, 2019) }\end{array}$ & $\begin{array}{l}\text { Existe a necessidade de aumentar a } \\
\text { representação e participação das mulheres na } \\
\text { orientação de futuras atividades para } \\
\text { desenvolvimento do ecoturismo. }\end{array}$ & Inexistente. & 7 \\
\hline $\begin{array}{l}\text { (Ariani, Zuska, } \\
\text { Manurung, } \\
\text { Ismail, \& } \\
\text { Munthe, 2019) }\end{array}$ & $\begin{array}{l}\text { Ecoturismo impacta positivamente no } \\
\text { empoderamento, mulheres são motivadas pelo } \\
\text { desejo de desempenhar um papel no setor } \\
\text { público, aumentar sua capacidade e melhorar a } \\
\text { renda. }\end{array}$ & Inexistente. & 2 \\
\hline (Hillman, 2019) & $\begin{array}{l}\text { Treinamento e habilidades empreendedoras } \\
\text { beneficiam o empoderamento das mulheres. }\end{array}$ & Inexistente. & 1 \\
\hline $\begin{array}{l}\text { (Díaz-Carrión, } \\
\text { Vizcaino- } \\
\text { Suárez, \& } \\
\text { Gaggiotti, 2020) }\end{array}$ & $\begin{array}{l}\text { A participação no turismo de aventura engaja as } \\
\text { mulheres em processo de resistência, contestam } \\
\text { tabus culturais ao feminino. As mulheres usam } \\
\text { os espaços liminares do turismo de aventura } \\
\text { para transformação, ou mesmo transgressão, } \\
\text { onde podem se separar da experiência } \\
\text { normativa. }\end{array}$ & $\begin{array}{l}\text { Pesquisas para analisar o papel } \\
\text { que redes privadas e públicas } \\
\text { desempenham no apoio à } \\
\text { construção de experiências não } \\
\text { normativas para mulheres no } \\
\text { turismo de aventura. }\end{array}$ & 0 \\
\hline $\begin{array}{l}\text { (Morgan \& } \\
\text { Winkler, 2020) }\end{array}$ & $\begin{array}{l}\text { Projetos de empoderamento feminino } \\
\text { continuam falhos, por não abordar normas e } \\
\text { restrições. }\end{array}$ & $\begin{array}{l}\text { Pesquisar barreiras do } \\
\text { empoderamento em outras formas } \\
\text { de atividades empresariais, } \\
\text { políticas ou recreativas. }\end{array}$ & 2 \\
\hline $\begin{array}{l}\text { (Buckley, } \\
\text { Shekari, } \\
\text { Mohammadi, } \\
\text { Azizi, \& Ziaee, } \\
\text { 2020) }\end{array}$ & $\begin{array}{l}\text { Ecoturismo impacta positivamente no } \\
\text { empoderamento. }\end{array}$ & $\begin{array}{l}\text { Pesquisa sobre dinâmica social e } \\
\text { diferenças larga escala e escala } \\
\text { local de turismo. }\end{array}$ & 7 \\
\hline $\begin{array}{l}\text { (Doran, } \\
\text { Schofield, \& } \\
\text { Low, 2020) }\end{array}$ & $\begin{array}{l}\text { A participação no alpinismo está sendo usada } \\
\text { como um meio de resistir às expectativas de } \\
\text { gênero e obter empoderamento. }\end{array}$ & $\begin{array}{l}\text { Pesquisas com relações de poder } \\
\text { de gênero e estratégias de } \\
\text { negociação. Explorar o papel das } \\
\text { mídias sociais na busca de } \\
\text { companheiras com o mesmo } \\
\text { objetivo, para conhecimentos } \\
\text { sobre o destino e rotas para ajudar } \\
\text { a superar uma série de restrições. }\end{array}$ & 4 \\
\hline $\begin{array}{l}\text { (Mendoza, } \\
\text { 2020) }\end{array}$ & $\begin{array}{l}\text { A indústria do ecoturismo facilitou a ascensão } \\
\text { de um sujeito masculino com base em valores } \\
\text { corporais fundamentais: fisicalidade robusta, } \\
\text { ética conservacionista e narração heroica sobre } \\
\text { a natureza selvagem envolvente. }\end{array}$ & Inexistente. & 1 \\
\hline $\begin{array}{l}\text { (M. Johnson, } \\
\text { 2020) }\end{array}$ & $\begin{array}{l}\text { Identifica o papel das mulheres crioulas que } \\
\text { serviam na esfera mais doméstica, assim como } \\
\text { empregadas e cozinheiras em lojas que } \\
\text { abrigavam pescadores. }\end{array}$ & Inexistente. & 1 \\
\hline
\end{tabular}




\begin{tabular}{|c|c|c|c|}
\hline Autoras & Conclusões & Sugestões para estudos futuros & Citações \\
\hline $\begin{array}{l}\text { (Nutsugbodo, } \\
\text { Adjei Mensah, } \\
\text { Amenumey, \& } \\
\text { Ansah Owusu, } \\
2020)\end{array}$ & $\begin{array}{l}\text { A existência de participação induzida e } \\
\text { coercitiva de mulheres residentes no projeto de } \\
\text { ecoturismo. }\end{array}$ & Inexistente. & 1 \\
\hline $\begin{array}{l}\text { (K.C, Dhakal, \& } \\
\text { Ghimire, 2020) }\end{array}$ & $\begin{array}{l}\text { Ecoturismo impacta positivamente no } \\
\text { empoderamento. }\end{array}$ & Inexistente. & 3 \\
\hline $\begin{array}{l}\text { (Fezeka \& } \\
\text { Stella, 2020) }\end{array}$ & $\begin{array}{l}\text { Aponta exploração do trabalho, desigualdade de } \\
\text { gênero, baixos salários e baixo nível de } \\
\text { escolaridade. }\end{array}$ & Inexistente. & 0 \\
\hline
\end{tabular}

Fonte: Elaborado pelos autores (2020).

Diante disso, é possível perceber que diversas pesquisas apontam para os impactos positivos trazidos pelo ecoturismo às residentes e trabalhadoras dos destinos turísticos estudados, apontando para um empoderamento dessas mulheres. Essas considerações também são encontradas em estudos da América Latina. De acordo com Díaz-Carrión (2014), por exemplo, em uma de suas análises realizadas no México, o ecoturismo pode ser efetivamente utilizado como uma ferramenta que dá voz e imagem, renda e segurança às mulheres, com o objetivo de aumentar sua participação como empreendedoras. Apesar dos benefícios citados, também há a constatação de impactos negativos como a exploração das trabalhadoras e a problemática da divisão do trabalho. O que ocorre é que as mulheres acabam por acumular funções, pois seguem com a responsabilidade dos trabalhos domésticos e familiares, considerados invisíveis (Gentry, 2007; Díaz-Carrión, 2014; Morgan \& Winkler, 2020; Fezeka \& Stella, 2020).

Outra comprovação identificada, nessa análise, foi quanto aos diversos benefícios trazidos às turistas do turismo de aventura na natureza, quando ocupam esses espaços que costumavam ser restritos aos homens. Entre eles, está o sentimento de autoconfiança, bem-estar e empoderamento feminino. Entretanto, também é observado, nos artigos, que ainda existem barreiras culturais, sociais e econômicas a serem vencidas pelas mulheres nesse segmento (Doran, Schofield, \& Low, 2018; Morgan \& Winkler, 2020). Nesse sentido, encontram-se também sugestões para que se façam mais estudos sobre a participação das mulheres no segmento de aventura, a fim de que se possa compreender melhor a dinâmica dessa participação, bem como, consiga-se identificar o papel de redes que fornecem apoio à construção de experiências não normativas para mulheres no turismo de aventura. Doran et al. (2020) sugerem que se explore mais o papel das mídias na inserção do público feminino.

Além disso, ainda analisando as sugestões para estudos futuros, percebe-se que parte considerável dos artigos, aqui estudados, sequer menciona alguma sugestão, o que demonstra 
um ponto fraco dessas pesquisas deixando-as menos consistentes, já que é de alta importância que se apresentem caminhos de pesquisa futuros, pois isso irá apontar, auxiliar e direcionar a evolução científica do tema gênero e turismo, principalmente quando o estudo publicado é qualitativo, dada a sua natureza eminentemente exploratória.

Também foi feita uma análise de autorias, onde foram levantados os países e filiações dos autores e coautores, no quadro 4, estão os que foram citados mais de uma vez.

\section{Quadro 4.}

Principais Autores Identificados nos Artigos Científicos Sobre Gênero e Turismo De Aventura e

Ecoturismo no Período de 1998 a Junho de 2020 da Base de Dados Scopus

\begin{tabular}{|l|l|l|r|}
\hline \multicolumn{1}{|c|}{ Autores e coautores } & \multicolumn{1}{|c|}{ Filiação } & \multicolumn{1}{c|}{ País } & \multicolumn{1}{c|}{ Artigos } \\
\hline Doran, A. & Sheffield Hallam University & Reino Unido & 3 \\
\hline Low, T. & Aberystwyth University & Reino Unido & 2 \\
\hline Schofield, P. & Sheffield Hallam University & Reino Unido & 2 \\
\hline Díaz-Carrión, I.A. & Universidad Autónoma de Baja California & México & 2 \\
\hline Hidalgo, A.-E & University of British Columbia & Canadá & 2 \\
\hline K. C, A., Amrit & Tribhuvan University & Nepal & 2 \\
\hline
\end{tabular}

Fonte: Elaborado pelos autores (2020).

Entre autores e coautores tem-se um total de 87 pessoas e 24 países, sendo esses: EUA (20), África do Sul (8), Canadá (9), Reino Unido (6), Indonésia (5), Austrália (4), Irã (4), Nepal (4), Nova Zelândia (4), Camarões (3), China (3), Espanha (2), Gana (2), Turquia (2), Albânia, Alemanha, Botsuana, Finlândia, Índia, Itália, Jamaica, Japão, México e Peru, esses últimos com um autor/coautor cada. Nota-se que as produções sobre o tema se encontram distribuídas entre várias instituições, pessoas e países, havendo autores de todos os continentes. Logo, esse fato reafirma o interesse da comunidade científica mundial. Reconhece-se que a autora com mais publicações é a Dra. Adele Doran da Sheffield Hallam University, suas pesquisas se concentram nas experiências de turistas de aventura e recreacionistas de aventura, principalmente em relação ao gênero. 
Santos, I. S., Borges, A. A., Scrivano, P., \& Freire, O. B. L. (2022, jan./abr.). O que sabemos sobre a relação das mulheres com o turismo de aventura e ecoturismo?

\section{Quadro 5.}

Fatores do Estudo de Cocitação Obtidos Por Meio da AFE Sobre Gênero e Turismo de Aventura e

Ecoturismo no Período de 1998 a Junho de 2020 da Base de Dados Scopus

\begin{tabular}{|c|c|c|c|c|c|c|c|}
\hline \multirow{2}{*}{ Estudos } & \multicolumn{6}{|c|}{ Componentes } & \multirow[t]{2}{*}{ Nome do Fator } \\
\hline & 1 & 2 & 3 & 4 & 5 & 6 & \\
\hline Weaver (2005) & 0,886 & & & & & & \multirow{7}{*}{$\begin{array}{c}\text { Políticas e Práticas do } \\
\text { Ecoturismo }\end{array}$} \\
\hline Belsky (1999) & 0,886 & & & & & & \\
\hline Stronza, (2005) & 0,873 & & & & & & \\
\hline Currie e Vernooy (2010) & 0,865 & & & & & & \\
\hline Dilly (2003) & 0,861 & & & & & & \\
\hline Swain e Swain (2004) & 0,850 & & & & & & \\
\hline Hall, Swain e Kinnaird (2003) & 0,819 & & & & & & \\
\hline Tosun (2006) & & 0,927 & & & & & \multirow{6}{*}{$\begin{array}{c}\text { Turismo e } \\
\text { Empoderamento }\end{array}$} \\
\hline Wilkinson e Pratiwi (1995) & & 0,846 & & & & & \\
\hline Acharya e Halpenny (2013) & & 0,842 & & & & & \\
\hline Khatiwada, Silva, (2015) & & 0,842 & & & & & \\
\hline Scheyvens (1999) & & 0,841 & & & & & \\
\hline Cole (2006) & & 0,837 & & & & & \\
\hline Doran (2016) & & & 0,914 & & & & \multirow{4}{*}{$\begin{array}{l}\text { Participação da Mulher } \\
\text { no Turismo de Aventura }\end{array}$} \\
\hline Kiewa (2001) & & & 0,853 & & & & \\
\hline Hudson (2000) & & & 0,853 & & & & \\
\hline Myers (2010) Annals & & & 0,716 & & & & \\
\hline Zambrano e Broadbent (2010) & & & & 0,787 & & & \multirow{3}{*}{$\begin{array}{l}\text { Meio Ambiente, } \\
\text { Turismo de Base } \\
\text { Comunitária e } \\
\text { Sustentabilidade }\end{array}$} \\
\hline Stone (2015) & & & & 0,787 & & & \\
\hline Nicholas e Thapa (2010) & & & & 0,787 & & & \\
\hline Kabeer (1999) & & & & & 0,830 & & \multirow{4}{*}{$\begin{array}{l}\text { Gênero e Turismo de } \\
\text { Base Comunitária }\end{array}$} \\
\hline Fletcher (2014) & & & & & 0,829 & & \\
\hline Afenyo e Amuquandoh (2014) & & & & & 0,767 & & \\
\hline Walter (2011) & & & & & 0,683 & & \\
\hline Granovetter (1973) & & & & & & 0,884 & \multirow{3}{*}{ Capital Social } \\
\hline Lin (2001) & & & & & & 0,826 & \\
\hline Key e Pillai (2006) & & & & & & 0,826 & \\
\hline $\begin{array}{l}\text { Variância Explicada do Fator } \\
\text { (\%) }\end{array}$ & 20,6 & 19,1 & 11,2 & 10,0 & 10,0 & 8,4 & \\
\hline $\begin{array}{l}\text { Variância Explicada } \\
\text { Acumulada (\%) }\end{array}$ & 20,6 & 39,7 & 50,9 & 60,9 & 70,9 & 79,3 & \\
\hline
\end{tabular}

Fonte: Elaborado pelos autores (2020).

Assim, o primeiro componente - Políticas e Práticas do Ecoturismo - aborda questões desde a formulação de políticas próprias para a formulação do ecoturismo, assim como, políticas relacionadas ao gênero e à comunidade local. Os artigos do componente 2 - Turismo e Empoderamento - apresentam o turismo como uma "ponte" para o empoderamento de comunidades, por meio de desenvolvimento econômico e de gênero. Apresenta-se um caminho para o turismo feminino, com entendimento sobre as relações de trabalho e gênero, tendo em 
vista a qualidade de vida, entre outros aspectos. O componente 3 - Participação da Mulher no Turismo de Aventura - apresenta uma grande lacuna dos estudos no turismo: o entendimento de como se dá a participação das mulheres. Esse componente é composto por artigos que buscam traçar diferenças de comportamentos entre homens e mulheres, assim como enaltecer a participação feminina, que valoriza o turismo como um todo. O componente 4 - Meio Ambiente, Turismo de Base Comunitária e Sustentabilidade - tem como pano de fundo o turismo de base comunitária, mas o que ele trata na superfície é como tal tipo de turismo é benéfico para a construção de um turismo mais responsável e sustentável, e como ele pode afetar atitudes e comportamentos dos turistas. Por meio de estudos mais específicos sobre o turismo de base comunitária, os artigos que formam o componente 5 preocupam-se com os processos e com as ferramentas para turismo feminino. Eles mapeiam as dimensões para a predileção do turismo feminino e para o empoderamento que tais escolhas dão às mulheres. Por fim, o componente 6 está relacionado ao Capital Social, o qual busca compreender os desdobramentos das identidades étnicas de maneira geral e no turismo.

Na sequência, vale salientar que foram realizadas as análises com o auxílio do software IRAMUTEQ®. A Nuvem de Palavras apresentou palavras mais frequentes dos artigos (Figura $3)$. 
Figura 3.

Nuvem de Palavras Construída a Partir dos Artigos Científicos Sobre Gênero e

Turismo de Aventura e Ecoturismo no Período de 1998 a Junho de 2020

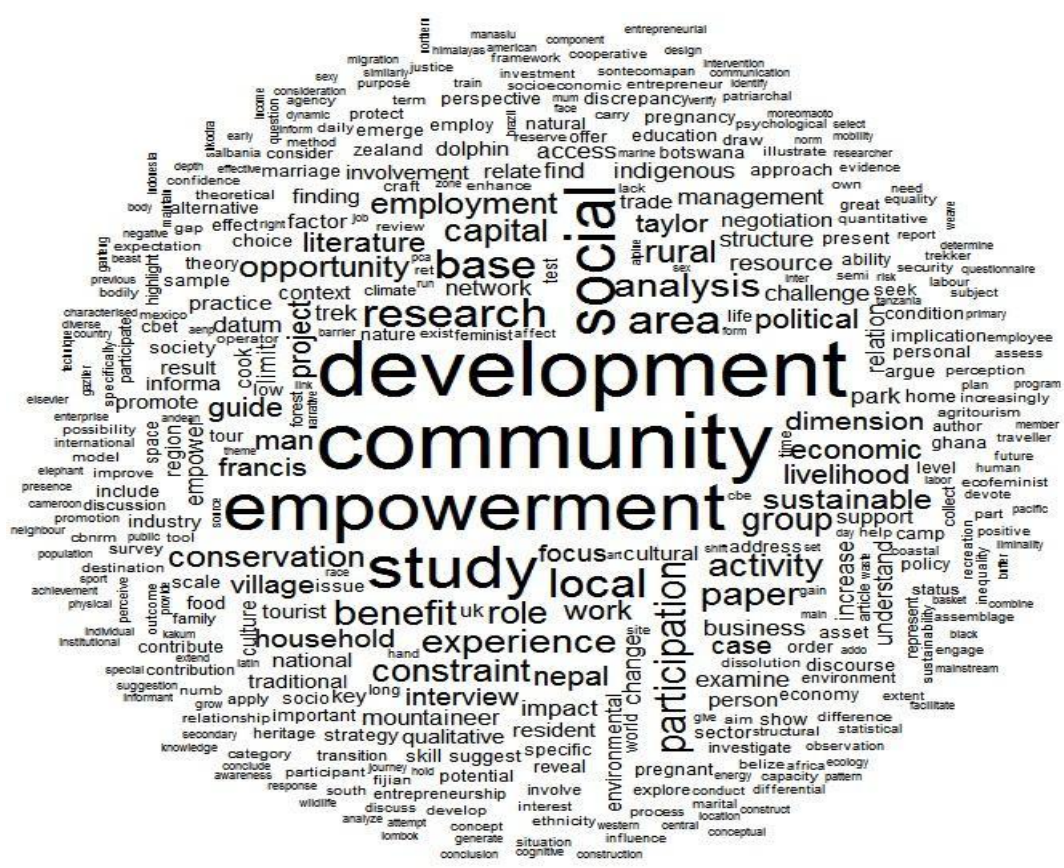

Fonte: Elaborada pelos autores (2020).

Dessa forma, percebe-se, então, o destaque para as palavras "desenvolvimento", "comunidade" e "empoderamento", afirmando novamente que a preocupação da maior parte dos artigos pesquisados foi com o desenvolvimento das comunidades associado ao empoderamento. Este é definido como um processo pelo qual as mulheres se organizam para aumentar sua autoconfiança, afirmar seu direito de ser independente, fazer suas próprias escolhas e controlar os recursos que ajudarão a desafiar e eliminar a subordinação (Rowlands, 1995). Logo, é evidente que a maior parte dos artigos analisa esse processo dentro das comunidades dos destinos turísticos ou dos possíveis destinos ligados ao ecoturismo e turismo de aventura.

Assim, como foi descrito anteriormente, 36 artigos focaram seus estudos nas residentes dos destinos turísticos, e 21 desses abordavam o empoderamento dessas mulheres a partir do turismo realizado na região. Evidentemente, a maioria apontou que existe, sim, um desenvolvimento positivo para as mulheres das comunidades turísticas, relatando diversos tipos de empoderamento. Movono e Dahles (2017) e Arroyo, Barbieri, Sotomayor e Knollenberg (2019), por exemplo, citam o econômico, social, psicológico e político. 
Santos, I. S., Borges, A. A., Scrivano, P., \& Freire, O. B. L. (2022, jan./abr.). O que sabemos sobre a relação das mulheres com o turismo de aventura e ecoturismo?

Ao analisar as classes obtidas no CHD, é possível identificar uma associação do foco dos estudos com certos segmentos turísticos (Figura 4).

Figura 4.

Classificação Hierárquica Descendente (CHD) Construída a Partir dos Artigos

Científicos Sobre Gênero e Ecoturismo e Aventura no Período de 1998 a Junho de 2020

\begin{tabular}{|c|c|c|c|c|c|c|c|c|}
\hline \multicolumn{3}{|c|}{$\begin{array}{l}\text { TURISMO DE AVENTURA } \\
\text { EXPERIÊNCIAS }\end{array}$} & \multicolumn{3}{|c|}{$\begin{array}{c}\text { AGROTURISMO } \\
\text { PAPEL DA MULHER }\end{array}$} & \multicolumn{3}{|c|}{$\begin{array}{c}\text { ECOTURISMO } \\
\text { IGUALDADE DE GÊNERO }\end{array}$} \\
\hline Palavra & \multicolumn{2}{|c|}{ f $\quad x^{2}$} & \multirow{2}{*}{$\begin{array}{l}\text { Palavra } \\
\text { área }\end{array}$} & \multirow{2}{*}{$\begin{array}{l}f \\
17\end{array}$} & & Palavra & $f$ & $x^{2}$ \\
\hline aventura & 30 & 48,74 & & & 20,34 & & 45 & 52,32 \\
\hline restrição & 11 & 20,02 & conservação & 09 & 18,82 & ecoturismo & 43 & 14,21 \\
\hline experiência & 19 & 18,70 & gestão & 08 & 16,60 & sustentabilidade & 10 & 14,16 \\
\hline alpinista & 07 & 16,40 & tradicional & 08 & 16,60 & projeto & 07 & 13,55 \\
\hline negociação & 07 & 16,40 & nivel & 06 & 12,27 & argumento & 06 & 11,53 \\
\hline trekking & 06 & 13.95 & educação & 06 & 13.95 & base & 12 & 10,91 \\
\hline guia & 10 & 12,09 & papel & 13 & 11,89 & sociedade & 05 & 9,54 \\
\hline gravidez & 05 & 11,54 & povoado & 08 & 10,92 & indústria & 05 & 9,54 \\
\hline dado & 07 & 10,31 & cultural & 05 & 10,15 & politica & 05 & 9,54 \\
\hline turista & 07 & 10,31 & artesanato & 05 & 10,15 & ferramenta & 05 & 9,54 \\
\hline beneficio & 17 & 10,27 & local & 14 & 9,83 & politico & 04 & 7,57 \\
\hline espaço & 04 & 9,17 & econômico & 09 & 8,30 & condição & 04 & 7,57 \\
\hline survey & 04 & 9,17 & crescimento & 09 & 8,30 & perspectiva & 04 & 7,57 \\
\hline representa & 04 & 9,17 & herança & 04 & 8,06 & discrepância & 04 & 7,57 \\
\hline contribuição & 04 & 9,17 & melhora & 04 & 8,06 & ecofeminismo & 04 & 7,57 \\
\hline teórica & 04 & 9,17 & agroturismo & 04 & 8,06 & justiça & 04 & 7,57 \\
\hline feminino & 16 & 8,37 & lugar & 04 & 8,06 & estrutura & 04 & 7,57 \\
\hline grávida & 06 & 8,03 & promoção & 04 & 8,06 & conceito & 04 & 7,57 \\
\hline pessoal & 06 & 8,03 & necessidade & 04 & 8,06 & desenvolvimento & 31 & 6,67 \\
\hline dimensão & 08 & 7,68 & doméstica & 06 & 6,87 & pesquisa & 22 & 6,51 \\
\hline entrevista & 10 & 7,66 & recurso & 06 & 6,87 & teoria & 06 & 6,36 \\
\hline participante & 03 & 6,83 & região & 06 & 6,87 & procura & 06 & 6,36 \\
\hline trekker & 03 & 6,83 & habilidade & 06 & 6,87 & emprego & 06 & 6,36 \\
\hline viajante & 03 & 6,83 & oportunidade & 10 & 6,30 & aplicação & 06 & 6,36 \\
\hline verifica & 03 & 6,83 & relação & 10 & 6,30 & empoderamento & 27 & 6,05 \\
\hline jornada & 03 & 6,83 & socioeconômico & 03 & 6,00 & igualdade & 03 & 5,64 \\
\hline atividade & 17 & 4,35 & comunidade & 23 & 4,14 & discussão & 03 & 5,64 \\
\hline & & & rural & 12 & 3,52 & social & 17 & 4,72 \\
\hline
\end{tabular}

Fonte: Elaborada pelos autores (2020). 
É importante afirmar que o teste do qui-quadrado $\left(\mathrm{x}^{2}\right)$ realizado pelo software indica o grau de associação entre a palavra e a classe, em outras palavras, quanto cada uma das palavras se relaciona com aquela classe que está inserida. Enquanto o f representa a frequência total da palavra no corpo do texto. Vale lembrar que foram desconsideradas as palavras não significantes estatisticamente. As classes originadas foram analisadas a partir dessas palavras e do Typical Text Segment, documento que resgata as frases que mais representam estatisticamente cada classe. Com isso, foi possível compreender o contexto de cada uma.

O primeiro aspecto notado é que cada uma das classes trazia consigo um segmento diferente em destaque, e que as ideias e focos dessas classes estavam conectados com esses segmentos. Os resultados da análise do CHD evidenciam um aspecto interessante, apesar do agroturismo não ter sido inserido nas palavras-chave da busca inicial, ele se destacou em diversos estudos, criando, inclusive, uma classe específica. Desse modo, a nomeação das classes se deu de acordo com tais segmentos e com o principal tema envolvido identificado.

Dessa forma, a classe 1 foi nomeada Turismo de Aventura - Experiências, pois representa principalmente as experiências das mulheres, no turismo de aventura, nota-se nela o destaque de palavras como aventura e experiência. Percebe-se, então, que esse segmento está mais interligado com as mulheres no papel de turista, com isso, observa-se que as palavras: participante, viajante e turista configuram-se, nessa classe.

É importante afirmar que essa classe destaca atividades mais específicas, dentro desse segmento, como o alpinismo, trekking e as viagens de mochileiras. Além disso, traz outro tema diferente, que é a gravidez, uma condição feminina que coloca a mulher em uma posição ainda mais delicada, fazendo um contraponto ainda maior com as atividades de aventura e estabelecendo um tabu nessa relação (Díaz-Carrión, Vizcaino-Suárez, \& Gaggiotti, 2020).

As palavras: barreiras, restrição e negociação exemplificam, muito bem, quais as principais discussões dentro desse tema, já que tal segmento é um espaço comumente dominado por homens, o que impõem certas barreiras e restrições às mulheres, havendo a necessidade de negociações. Também nesse sentido, os estudos com foco na aventura em si, colocam essa atividade como forma de experiências que tendem trazer benefícios às mulheres. (Myers, 2010; Doran 2016; Mendoza, 2020; Díaz-Carrión, Vizcaino-Suárez, \& Gaggiotti, 2020).

Ademais, verifica-se que a classe 2 foi intitulada de Agroturismo - Papel das Mulheres, já que tem como principal conteúdo a descrição do papel tradicional da mulher dentro das zonas rurais. Logo, o destaque das palavras: cultural, herança, papel, tradicional, conservação, habilidade, artesanato e doméstica estão reforçando essa ideia. Nela há a descrição de atividades 
como artesanato e outras atividades domésticas, as quais são vistas historicamente como femininas (A. M. Johnson, 1999; Cudmore, Troshani, \& McCoy, 2009; Díaz-Carrión, 2014; M. Johnson, 2020). Por conseguinte, identifica-se, aqui, a divisão sexual de trabalho e demonstra, como na zona rural, esse problema é ainda mais acentuado. Assim, quando se fala em agroturismo, costuma-se colocar as mulheres como protagonistas de serviços domésticos, o contrário do que acontece nos artigos que estão relacionados com a atividade de aventura.

Essa classe, diferente da primeira, foca mais nas residentes dos destinos de turismo, destaque para palavras como local, lugar, área, comunidade, povoado e rural, que remetem ao vínculo dessas mulheres com o espaço rural onde vivem. Percebe-se, também, o destaque para palavras como: econômico, socioeconômico, promoção, melhora e crescimento, o que remete à possibilidade de aliar o papel tradicional das mulheres com o agroturismo para obter benefícios, especialmente financeiros, nas comunidades locais rurais (Külekçi, Sezen, \& Bulut, 2012).

Já a classe 3 foi chamada de Ecoturismo - Igualdade de Gênero, por ter como enfoque essa questão. Envolvem-se, nela, palavras como gênero, política/político, desenvolvimento estrutura, indústria, emprego, sociedade, justiça, discrepância e igualdade; elementos que demonstram esse foco mais amplo em questões políticas da sociedade relacionadas ao problema da desigualdade de gênero (Hidalgo et, al, 2018).

Além disso, também há destaque em palavras como: ferramenta, projetos e empoderamento, pois trazem projetos que visam ao desenvolvimento baseado no empoderamento feminino. Os artigos dessa classe estão mais ligados ao desenvolvimento de atividades do ecoturismo como ferramenta que pode beneficiar as mulheres envolvidas, principalmente quanto à econômica, demonstrando formas de torná-las mais independentes financeiramente a partir do desenvolvimento do turismo, e por consequência, melhorando sua autoconfiança (Tran \& Walter, 2014). Aqui também se nota que essa terceira classe assim como a segunda estão mais centradas na mulher no papel de residente de um destino turístico.

Outro tema é a questão ambiental, em destaque nesse grupo, no qual apresentam-se palavras como sustentabilidade e o ecofeminismo. Esse último é uma vertente do movimento feminista que faz essa conexão entre a luta pela igualdade de direitos e oportunidades entre homens e mulheres e a defesa do meio ambiente (Swain \& Swain, 2004).

Portanto, ao analisar as três classes, de forma conjunta, é possível notar que as pesquisas seguem abordando mais essa relação das mulheres com o âmbito doméstico e locais e atividades mais tradicionalmente ligadas ao feminino, pois há destaque nos segmentos mais softs, como 
agroturismo e o ecoturismo. Nota-se, inclusive, que essas classes estão mais próximas entre si, enquanto a classe da aventura, a qual traz atividades mais hard, está mais distante e costuma fazer uma relação diferente entre a mulher e o segmento em questão. Dessa forma, é visto um ponto em comum em todas as classes, que é justamente a preocupação em auxiliar as mulheres em melhorar a sua condição, seja como turista, no âmbito considerado fora de seu domínio que seria a aventura tirando-as de seu tradicional papel, ou como residente, utilizando esse papel tradicional em seu benefício.

\section{Conclusão}

Conclui-se que o presente artigo atingiu o objetivo de analisar o estado da arte da produção científica sobre as mulheres e sua relação com o turismo de aventura e ecoturismo. A partir desse estudo, foi possível perceber que este é um campo efervescente, mas que ainda apresenta poucos estudos e, em sua maioria, de abordagens qualitativas. Entretanto, há um crescimento no número de publicações, e estas já se configuram em periódicos científicos de impacto, demonstrando o caráter promissor do tema. Outro aspecto é a variedade desses periódicos, evidenciando que há um vasto campo para publicações. Além disso, também foram analisadas as principais sugestões feitas pelos autores para estudos futuros, o que auxiliam no desenvolvimento da ciência para o tema em questão.

Assim, os estudos trazem resultados que apontam para benefícios do turismo de aventura e ecoturismo para as mulheres. Dentre eles estão o empoderamento econômico, social, político e psicológico destacando a questão da autoestima das turistas e residentes. Além disso, foram identificadas diversas barreiras a serem ultrapassadas, para que as mulheres consigam ocupar novos espaços e cheguem mais perto da igualdade de gênero. Logo, é possível perceber que quando se fala em atividades de aventura, logo são apresentados os pontos positivos trazidos pelas experiências aos grupos de turistas mulheres. Já quando se refere ao ecoturismo, o outro lado é abordado, o grupo das residentes dos destinos turísticos. É notório afirmar que houve, também, um destaque para o segmento do agroturismo, que descreve os tradicionais papéis femininos.

Portanto, verifica-se que a maioria dos estudos relacionam as mulheres com o ecoturismo e agroturismo, e poucos abordam o turismo de aventura mais hard - apenas sete dos 43 artigos encontrados - demonstrando que há uma lacuna nesse tema. Assim, sugere-se que estudos futuros preencham essa lacuna, como também, novas pesquisas sejam realizadas, 
a fim de que incluam bases científicas do Brasil, ou de outros países da América Latina, para compreender também essas regiões. Além da possibilidade de inclusão de palavras-chave referentes a outras segmentações do turismo.

\section{Referências}

Acharya, B. P., \& Halpenny, E. A. (2013). Homestays as an alternative tourism product for sustainable community development: A case study of women-managed tourism product in rural Nepal. Tourism Planning \& Development, 10(4), 367-387. https://doi.org/10.1080/21568316.2013.779313

Afenyo, E. A., \& Amuquandoh, F. E. (2014). Who benefits from community-based ecotourism development? Insights from TafiAatome, Ghana. Tourism Planning \& Development, 11 (2), 179-190. https://doi.org/10.1080/21568316.2013.864994

Ariani, D., Zuska, F., Manurung, R., Ismail, R., \& Munthe, H. M. (2019). Village woman in sembalun lawang ecotourism area, at the foot of rinjani volcano, east lombok, indonesia. International Journal of Scientific and Technology Research, 8(12), 11521160. https://ijstr.org/research-paper-publishing.php?month=dec2019

Arroyo, C. G., Barbieri, C., Sotomayor, S., \& Knollenberg, W. (2019). Cultivating women's empowerment through agritourism: Evidence from Andean communities. Sustainability (Switzerland), 11(11), 1-14. https://doi.org/10.3390/su11113058

Bardin, L. (1977). Análise de conteúdo. Edições 70. Belsky, J. (2009). Misrepresenting Communities: The Politics of Community-Based Rural Ecotourism in Gales Point Manatee, Belize. Rural Sociology, 64(4), 641-666. https://doi.org/10.1111/j.15490831.1999.tb00382.x

Besio, K., Johnston, L., \& Longhurst, R. (2008). Sexy beasts and devoted mums: Narrating nature through dolphin tourism. Environment and Planning A, 40(5), 1219-1234. https://doi.org/10.1068/a38424

Boley, B. B., Ayscue, E., Maruyama, N., \& Woosnam, K. M. (2017). Gender and empowerment: Assessing discrepancies using the resident empowerment through tourism scale. Journal of Sustainable Tourism, 25(1), 113-129. https://doi.org/10.1080/09669582.2016.1177065

Buckley, R., Shekari, F., Mohammadi, Z., Azizi, F., \& Ziaee, M. (2020). World heritage tourism triggers urban-rural reverse migration and social change. Journal of Travel Research, 59(3), 559-572. https://doi.org/10.1177/0047287519853048

Camargo, B. V., \& Justo, A. M. (2013). IRAMUTEQ: Um software gratuito para análise de dados textuais. Temas Em Psicologia, 21(2), 513-518. https://doi.org/10.9788/tp2013.2-16

Chamberlain, P. (2017). The feminist fourth wave: Affective temporality. Palgrave Macmillan. 
Cheng, M., Edwards, D., Darcy, S., \& Redfern, K. (2016). A Tri-Method Approach to a Review of Adventure Tourism Literature: Bibliometric Analysis, Content Analysis, and a Quantitative Systematic Literature Review. Journal of Hospitality \& Tourism Research, 42(6), 997-1020. https://doi:10.1177/1096348016640588

Cobo, M. J., López-Herrera, A. G., Herrera-Viedma, E., \& Herrera, F. (2011). Science mapping software tools: Review, analysis, and cooperative study among tools. Journal of the American Society for Information Science and Technology, 62(7), 1382-1402. https://doi.org/10.1002/asi.21525

Cochrane, K. (2014). All the Rebel Women: The rise of the fourth wave of feminism. Guardian Books.

Cole, S. (2006). Information and Empowerment: The keys to achieving sustainable tourism. Journal of Sustainable Tourism, 14 (6), 629-644. https://doi.org/10.2167/jost607.0

Cudmore, B. A., Troshani, A., \& McCoy, J. (2009). Entrepreneurial investment in the shkodra region: Opportunities for women in tourism. Entrepreneurial Executive, 14(1), 31-47. https://www.abacademies.org/journals/month-june-year-2009-vol-14-issue-1-journalee-past-issue.html

Currie, D. H., \& Vernooy, R. (2010). Social and gender analysis in development practice gender, technology and development, 14(1), 1-23. https://doi.org/10.1177/097185241001400101

Datta, P. B. \& Gailey, R. (2012). Empowering women through social entrepreneurship: Case study of women's cooperative in India. Entrepreneurship Theory and Practice. 36(3), 569-587. https://doi.org/10.1111/j.1540-6520.2012.00505.x

Díaz-Carrión, I. A. (2014). Ecoturismo y vida cotidiana de las mujeres en Sontecomapan (Veracruz, México). Cuadernos de Turismo, (34), 69-88. http://revistas.um.es/turismo/article/view/203031

Díaz-Carrión, I. A., Vizcaino-Suárez, P., \& Gaggiotti, H. (2020). Change within the change: Pregnancy, liminality and adventure tourism in Mexico. Tourism Geographies, 22(2), 370-391. https://doi.org/10.1080/14616688.2020.1713876

Dilly, B. J. (2003). Gender, culture, and ecotourism: development policies and practices in the guyanese rain forest. Women's. Studies Quarterly, 31(3/4), 58-75.

http://www.jstor.org/stable/40003320

Doran, A. (2016). Empowerment and women in adventure tourism: A negotiated journey. Journal of Sport and Tourism, 20(1), 57-80. https://doi.org/10.1080/14775085.2016.1176594

Doran, A., Schofield, P., \& Low, T. (2018). Women's mountaineering tourism: An empirical investigation of its theoretical constraint dimensions. Leisure Studies, 37(4), 396-410. https://doi.org/10.1080/02614367.2018.1452283 
Doran, A., Schofield, P., \& Low, T. (2020). Women's mountaineering: Accessing participation benefits through constraint negotiation strategies. Leisure Studies, 39(5), 1-15. https://doi.org/10.1080/02614367.2020.1763439

Elsevier. (2020). Scopus. Elsevier. https://www.elsevier.com/pt-br/solutions/scopus

Ferguson, L., \& Alarcón, D. M. (2015). Gender and sustainable tourism: Reflections on theory and practice. Journal of Sustainable Tourism, 23(3), 401-416. https://doi.org/10.1080/09669582.2014.957208

Fezeka, M., \& Stella, K. A. (2020). Assessment of the socio-economic impacts of Tourism on three rural communities neighbouring addo elephant national park, Eastern Cape, South Africa. African Journal of Hospitality, Tourism and Leisure, 9(1), 1-19. https://www.ajhtl.com/uploads/7/1/6/3/7163688/article_76_vol_9_1_2020_ufh.pdf

Field, A. (2009). Descobrindo a estatística usando o SPSS. Bookman Editora.

Figueroa-Domecq, C., Pritchard, A., Segovia-Pérez, M., Morgan, N., \& Villacé-Molinero, T. (2015). Tourism gender research: A critical accounting. Annals of Tourism Research, 52, 87-103. https://doi:10.1016/j.annals.2015.02.001

Fletcher, R., (2014) Romancing the wild: Cultural dimensions of ecotourism, Duke University Press.

Gentry, K. M. K. (2007). Belizean women and tourism work. Opportunity or Impediment? Annals of Tourism Research, 34(2), 477-496. https://doi.org/10.1016/j.annals.2006.11.003

Glick, P., \& Fiske, S. T. (1996). The ambivalent sexism inventory: Differentiating hostile and benevolent sexism. Journal Od Personality and Social Psychology, 70(3), 491-512. https://doi.org/10.1037/0022-3514.70.3.491

Gomes, M. M.; Brochado, M.; \& Lipovestsky, N. (2014). Curso de Aperfeiçoamento Paideia Jurídica na Escola: Educação em direitos humanos para uma consciência jurídica cidadã. CAED/UFMG.

Granovetter, M. S. (1973). The Strength of Weak Ties. American Journal of Sociology, 78 (6), 1360-1380. https://www.journals.uchicago.edu/doi/abs/10.1086/225469

Hair, H. F., Anderson, R. E., Tatham, R. L., \& Black, W. (1998). Multivariate Data Analysis. (5) Prentice Hall.

Hall, D., Swain, M. B., \& Kinnaird, V. (2003). Tourism and Gender: An evolving agenda. Tourism Recreation Research, 28(2), 7-11. https://doi.org/10.1080/02508281.2003.11081399

Hidalgo, R., Elia, A., \& Harris, L. M. (2018). Social Capital, political empowerment and social difference: A mixed-methods study of an ecotourism project in the rural Volta 
region of Ghana. Journal of Sustainable Tourism, 26(12), 2153-2172.

https://doi.org/10.1080/09669582.2018.1546711

Hidalgo, R., Elia, A., Kozak, R. A., Harshaw, H. W., \& Tindall, D. B. (2018). Differential Effects of Cognitive and Structural Social Capital on Empowerment in Two Community Ecotourism Projects in Ghana. Society and Natural Resources, 31(1), 5773. https://doi.org/10.1080/08941920.2017.1364454

Hillman, W. (2019). Issues for women trekking in Nepal: '3 sisters adventure trekking' guides. Journal of Sport and Tourism, 23(1), 1-18. https://doi.org/10.1080/14775085.2019.1593226

Hirtenfelder, C. T. (2016). Cooking in tourism and at home: Unpacking the contours of different gender orders in Moreomaoto, Botswana. Tourism, 64(4), 431-444. https://www.researchgate.net/publication/311735516_Cooking_in_tourism_and_at_ho me_Unpacking_the_contours_of_different_gender_orders_in_Moreomaoto_Botswana

Hirtenfelder, C. T. (2017). Strength, mobility, and variety: Central discourses which undermine tourism's ability to subvert broader gender orders in Botswana. African Studies, 76(1), 64-85. https://doi.org/10.1080/00020184.2017.1285668

Hudson, S. (2000). The Segmentation of Potential Tourists: Constraint Differences Between Men and Women. Journal of Travel Research, 38, 363-368.

https://doi.org/10.1177/004728750003800404

IBGE (2020). Pesquisa Nacional por Amostra de Domicílios (PNAD) 2019. Instituto Brasileiro de Geografia e Estatística. https://www.ibge.gov.br/estatisticas/sociais/trabalho/9171-pesquisa-nacional-poramostra-de-domicilios-continua-mensal.html?=\&t=o-que-e

Johnson, A. M. (1997). The basket weaving tradition in the communities of the Black River Lower Morass, Jamaica. Caribbean Geography, 8(2), 66-80. https://www.proquest.com/docview/232173692?pqigsite $=$ gscholar $\&$ fromopenvie $\mathrm{w}=$ true

Johnson, M. (2020). Gender, Race and Ecotourism Assemblages in Rural Creole Belize. Bulletin of Latin American Research, 39(2), 175-190. https://doi.org/10.1111/blar.12883

Jordan, F., \& Gibson, H. (2005). 'We're not stupid ut we'll not stay home either': Experiences of solo women travellers. Tourism Review International, 9(2), 195-212. https://doi.org/10.3727/154427205774791663

Kabeer, N. (1999). Resources, Agency, Achievements: Reflections on the measurement of women's empowerment. Development and Change, 30(3), 435-464. https://doi.org/10.1111/1467-7660.00125

Kamat, V. R., \& Woo Kinshella, M. L. (2018). Food insecurity and coping strategies in a marine protected area in southeastern Tanzania. Ecology of Food and Nutrition, 57(3), 
Santos, I. S., Borges, A. A., Scrivano, P., \& Freire, O. B. L. (2022, jan./abr.). O que sabemos sobre a relação das mulheres com o turismo de aventura e ecoturismo?

187-205. https://doi.org/10.1080/03670244.2018.1455672

Kane, M. J., \& Tucker, H. (2010). Adventure Tourism Market Report. Tourist Studies, 4(3), 217-234. https://doi.org/10.1177/1468797604057323

K. C, A., Dhakal, A., \& Ghimire, S. (2020). Ecotourism and its impact on indigenous people and their local environment: case of Ghalegaun and Golaghat of Nepal. GeoJournal, 86, 2747-2765. https://doi.org/10.1007/s10708-020-10222-3

K. C, A., \& Thapa Parajuli, R. B. (2014). Tourism and its impact on livelihood in Manaslu conservation area, Nepal. Environment, Development and Sustainability, 16(5), 10531063. https://doi.org/10.1007/s10668-013-9512-7

Key, C. J., Pillai, V. (2006). Community Participation and Tourism Attitudes in Belize Interamerican. Journal of EnvironmentaAnd Tourism, 2(2), 8-15. https://rc.library.uta.edu/utar/bitstream/handle/10106/25746/Community\%20Participat ion-Belize.pdf?sequence $=1$

Khatiwada, L. K., Silva, J. A. (2015). Mitigating Gender Inequality in Rural Regions: The Effects of Tourism Employment in Namibia. International Journal of Tourism Research, 17 (5), 442-450. https://doi.org/10.1002/jtr.2010

Kiewa, J. (2001).Stepping around Thingsâ: Gender Relationships in Climbing Australian. Journal Of Outdoor Education, 5 (2), 4-12. https://doi.org/10.1007/BF03400728

Kimengsi, J. N., Kechia, M. A., Azibo, B. R., Pretzsch, J., \& Kwei, J. (2019). Households' assets dynamics and ecotourism choices in the Western Highlands of Cameroon. Sustainability (Switzerland), 11(7), 1-16. https://doi.org/10.3390/su11071844

Koseoglu, M. A., Rahimi, R., Okumus, F., \& Liu, J. (2016). Bibliometric studies in tourism. Annals of Tourism Research, 61, 180-198. doi:10.1016/j.annals.2016.10.006

Külekçi, E. A., Sezen, I., \& Bulut, Y. (2012). The role of women in rural tourism, the sample of Gaziler village (Bardiz), Erzurum, Turkey. Journal of Food, Agriculture and Environment, 10(2), 1314-1319. https://doi.org/10.7784/rbtur.v12i3.1446

Lenao, M., \& Basupi, B. (2016). Ecotourism development and female empowerment in Botswana: A review. Tourism Management Perspectives, 18, 51-58. https://doi.org/10.1016/j.tmp.2015.12.021

Lin, N., (2001) Social Capital: A Theory of Social Structure and Action. Cambridge University Press.

Loubère, L., \& Ratinaud, P. (2014). Manual do aplicativo IRaMuTeQ. IRaMuTeQ http://www.iramuteq.org/documentation/html

Luo, L., Arizmendi, C., \& Gates, K. M. (2019). Exploratory Factor Analysis (EFA) Programs in R. Structural Equation Modeling, 26(5), 819-826. https://doi.org/10.1080/10705511.2019.1615835 
Maclaran, P. (2015). Feminism's fourth wave: a research agenda for marketing and consumer research. Journal of Marketing Management, 1732-1738. https://doi.org/10.1080/0267257X.2015.1076497

Marinho, A. (2006). As diferentes interfaces da aventura na natureza: Reflexões sobre a sociabilidade na vida contemporânea Universidade Estadual de Campinas.

McArthur, M. (1999). Out of place: Gender, identity and space, and the experiences of contemporary solo women travellers. Trent University Peterborough.

McBurney, M. K. \& Novak, P. L. (2002). What is bibliometric and why should you care? Proceedings. IEEE. International Communication Conference. 108-114. https://doi:10.1109/ipcc.2002.1049094

Medeiros, M. A. (2014). The other end if the bargain: The socioeconomics of marital dissolution in rural northeast Brasil. Journal of the Association of Black Anthropologists, 22(2), 105-120. https://doi.org/10.1111/traa.12032.105

Mejía Vázquez, R., Serrano Barquín, R. D. C., Osorio González, M., \& Favila Cisneros, H. (2019). Turismo y género: Una aproximación al estado de conocimiento. Cuadernos de Turismo, 38 (2016), 485-501. http://dx.doi.org/10.6018/turismo.38.271531

Mendoza, M. (2020). Alpine Masculinity: A Gendered Figuration of Capital in the Patagonian Andes. Bulletin of Latin American Research, 39(2), 208-222. https://doi.org/10.1111/blar.12839

Ministério do Turismo. (2010). Perfil do Turista de Aventura e do Ecoturista no Brasil. Associação Brasileira das Empresas de Turismo de Aventura. images/abook/pdf/2sem2015/setembro/Perfil do Ecoturista e do Turista de Aventura no Brasil 2010.pdf

Morgan, M. S., \& Winkler, R. L. (2020). The Third Shift? Gender and Empowerment in a Women's Ecotourism Cooperative. Rural Sociology, 85(1), 137-164. https://doi.org/10.1111/ruso.12275

Movono, A., \& Dahles, H. (2017). Female empowerment and tourism: a focus on businesses in a Fijian village. Asia Pacific Journal of Tourism Research, 22(6), 681-692. https://doi.org/10.1080/10941665.2017.1308397

Myers, L. (2010). Women travellers' adventure tourism experiences in New Zealand. Annals of Leisure Research, 13(1-2), 116-142. https://doi.org/10.1080/11745398.2010.9686841

Nicholas, L., Thapa, B. (2010). Visitor Perspectives on Sustainable Tourism Development in the Pitons Management Area World Heritage Site, St. Lucia. Environment, Development And Sustainability, 12 (5), 839-857. https://doi.org/10.1007/s10668-0099227-y 
Nichols, J., O’Brien, C., \& Heimlich, J. E. (1998). Why women are conservation leaders in rural Costa Rica. International Forestry, 96(12), 24-28. https://doi.org/10.1093/jof/96.12.24

Ntanjana, A., Maleka, M., Tshipala, N., \& du Plessis, L. (2018). Employment condition differences based on gender: A case of adventure tourism employees in Gauteng, South Africa. African Journal of Hospitality, Tourism and Leisure, 7(4), 1-16. https://www.ajhtl.com/uploads/7/1/6/3/7163688/article_49_vol_7_4_2018.pdf

Nutsugbodo, R. Y., Adjei Mensah, C., Amenumey, E. K., \& Ansah Owusu, C. (2020). Women's Participation in Ecotourism Development Within the Kakum Conservation Area, Ghana: Implications for Community Planning. Tourism Planning and Development, 17(6), 1-18. https://doi.org/10.1080/21568316.2020.1751693

OECD (2019), OECD Employment Outlook 2019: The Future of Work, OECD Publishing. https://doi.org/10.1787/9ee00155-en

Ogra, M. V., \& Badola, R. (2015). Gender and climate change in the Indian Himalayas: Global threats, local vulnerabilities, and livelihood diversification at the Nanda Devi Biosphere Reserve. Earth System Dynamics, 6(2), 505-523. https://doi.org/10.5194/esd-6-505-2015

Panta, S. K., \& Thapa, B. (2018). Entrepreneurship and women's empowerment in gateway communities of Bardia National Park, Nepal. Journal of Ecotourism, 17(1), 20-42. https://doi.org/10.1080/14724049.2017.1299743

Quevedo-Silva, F., Santos, E. B. A., Brandão, M. M., \& Vils, L. (2016). Estudo bibliométrico: orientações sobre sua aplicação. Revista Brasileira de Marketing, 15(2), 246-262. https://doi.org/10.5585/remark.v15i2.3274

Risman, B. J. (2017). Where the Millennials Will Take Us: A New Generation Wrestles with the Gender Structure. Oxford University Press.

Rowlands, J. (1995). Empowerment Examined. Development in Practice, 5(2), 101-107. https://doi.org/10.1080/0961452951000157074

Sampaio, T. M. V., \& Bahia, M. C. (2007). Lazer - Meio Ambiente. Em Busca das Atitudes Vivenciadas nos Esportes de Aventura. Revista Brasileira de Ciências Do Esporte, 28(3), 173-189. http://revista.cbce.org.br/index.php/RBCE/article/view/30/37

Schellhorn, M. (2010). Development for whom? Social justice and the business of ecotourism. Journal of Sustainable Tourism, 18(1), 115-135. https://doi.org/10.1080/09669580903367229

Scheyvens, R. (1999) Ecotourism and the Empowerment of Local Communities. Tourism Management, 20 (2), 245-249. https://doi.org/10.1016/S0261-5177(98)00069-7

Scheyvens, R. (2000). Promoting women's empowerment through involvement in ecotourism: Experiences from the third world. Journal of Sustainable Tourism, 8(3), 


\section{2-249. https://doi.org/10.1080/09669580008667360}

Schwartz, G. M., Pereira, L. M., Figueiredo, J. de P., Christofoletti, D. F. A., \& Dias, V. K. (2016). Estratégias de participação da mulher nos esportes de aventura. Revista Brasileira de Ciencias do Esporte, 38(2), 156-162. https://doi.org/10.1016/j.rbce.2015.11.007

Scimago Journal \& Country Rank. (2020). Journal Rank. Scimago Journal \& Country Rank. https://www.scimagojr.com/index.php

Souza, M. A. R. de, Wall, M. L., Thuler, A. C. de M. C., Lowen, I. M. V., \& Peres, A. M. (2018). O uso do software IRAMUTEQ na análise de dados em pesquisas qualitativas. Revista da Escola de Enfermagem da USP, 52 (e03353), 1-7. https://doi.org/10.1590/S1980-220X2017015003353

Stone, M. T. (2015). Community-Based Ecotourism: A Collaborative Partnerships Perspective. Journal Of Ecotourism, 14 (2/3), 166-184. https://doi.org/10.1080/14724049.2015.1023309

Stronza, A. (2005). Hosts and Hosts: The Anthropology of Community-Based Ecotourism in The Peruvian Amazon. National Association for Practice of Anthropology Bulletin, 23 (1), 170-190. https://doi.org/10.1525/napa.2005.23.1.170

Swain, M. B., \& Swain, M. T. B. (2004). An ecofeminist approach to ecotourism development. Tourism Recreation Research, 29(3), 1-6. https://doi.org/10.1080/02508281.2004.11081451

The Pacific Partnership. (2019). Shaping the Future of Adventure and Cultural Travel: Profiles and behaviors of adventure and cultural travelers from the United States and Australia. The pacific partnership.

Thomson Reuters Foundation. (2018). Factbox: Which are the world's 10 most dangerous countries for women?. Reuters. https://www.reuters.com/article/us-women-dangerouspoll-factbox/factbox-which-are-the-worlds-10-most-dangerous-countries-for-womenidUSKBN1JM01Z

Tosun, C. (2006). Expected Nature of Community Participation in Tourism Development. Tourism Management, 27 (3), 493-504.

Tran, L., \& Walter, P. (2014). Ecotourism, gender and development in northern Vietnam. Annals of Tourism Research, 44(1), 116-130. https://doi.org/10.1016/j.annals.2013.09.005

United Nations Organization. (2018). The Sustainable Development Goals "Goal 5: Achieve gender equality and empower all women and girls.” United Nations. https://www.un.org/sustainabledevelopment/gender-equality/

Vizcaíno, L. P., Serrano, R., Cruz, G., \& Pastor, M. J. (2016). Teorías y métodos en la investigación sobre turismo, género y mujeres en iberoamérica: Un análisis 
Santos, I. S., Borges, A. A., Scrivano, P., \& Freire, O. B. L. (2022, jan./abr.). O que sabemos sobre a relação das mulheres com o turismo de aventura e ecoturismo?

bibliográfico. Cuadernos de Turismo, (38), 485-501.

https://doi.org/10.6018/turismo.38.271531

Voopter. (2018). [Folder sobre viagens de mulheres]. Viaje Mulher.

https://cloud.voopter.com.br/viajemulher/pdf/Viaje-mulher.pdf

Walter, P. (2011). Gender analysis in community-based ecotourism. Tourism Recreation Research, 36(2), 159-168. https://doi.org/10.1080/02508281.2011.11081316

Weaver, D. (2005). Comprehensive and Minimalist Dimensions of Ecotourism. Annals Of Tourism Research, 32 (2), 439-455. https://doi.org/10.1016/j.annals.2004.08.003

Wilkinson, P. F., Pratiwi, W. (1995). Gender and Tourism in an Indonesian Village. Annals Of Tourism Research, 22 (2), 283-299. https://doi.org/10.1016/0160-7383(94)00077-8

Wilson, E., \& Little, D. (2005). A 'relative escape'? The Impact of Constraints on Women who Travel Solo. Tourism Review International, 9(2), 155-174. https://doi.org/1 $0.3727 / 154427205774791672$

World Tourism Organization. (2014). Global Report on Adventure Tourism (9th ed.). W. T. O. (UNWTO).

Zambrano, A. M. A., Broadbent, E. N., \& Durham, W. H. (2010). Social and Environmental Effects of Ecotourism in The Osa Peninsula of Costa Rica: The Lapa Rios Case. Journal of Ecotourism, 9 (1), 62-83. https://doi.org/10.1080/14724040902953076

Zeng, F., Zhou, C., \& Zhong, Y. (2018). Ecotourism Development and the Egocentric Network of Female Residents: A Case Study in Zhangjiajie National Forest Park. Journal of China Tourism Research, 14(4), 484-500. https://doi.org/10.1080/19388160.2018.1511491

Zupic, I., \& Čater, T. (2015). Bibliometric methods in management and organization. Organizational research methods, 18(3), 429-472. https://doi.org/10.1177/1094428114562629 